\title{
Photocatalytic water splitting ability of Fe/MgO-rGO nanocomposites towards hydrogen evolution
}

\author{
Fahmida Sharmin, Dayal Chandra Roy and M. A. Basith* \\ Nanotechnology Research Laboratory, Department of Physics, \\ Bangladesh University of Engineering and Technology, \\ Dhaka-1000, Bangladesh.
}

\begin{abstract}
Photocatalytic water splitting has greatly stimulated as an ideal technique for producing hydrogen $\left(\mathrm{H}_{2}\right)$ fuel by employing two renewable sources, i.e., water and solar energy. Here, we have adopted a facile hydrothermal approach for the successful synthesis of reduced graphene oxide (rGO) incorporated $\mathrm{Fe} / \mathrm{MgO}$ nanocomposites followed by thermal treatment at inert atmosphere to investigate their ability for photodegradation and photocatalytic hydrogen evolution via water splitting. Transmission Electron Microscopy images of Fe/MgO-rGO nanocomposite ensured the distribution of $\mathrm{Fe} / \mathrm{MgO}$ nanoparticles throughout rGO sheets. Notably, all rGO supported nanocomposites, especially the one, thermally treated at $500{ }^{\circ} \mathrm{C}$ at Argon (Ar) atmosphere has demonstrated significantly higher photocatalytic efficiency towards the photodegradation of a toxic textile dye, rhodamine B, than pristine $\mathrm{MgO}$ and commercially available Degussa P25 titania nanoparticles as well as other composites. Under solar irradiation, $\mathrm{Fe} / \mathrm{MgO}-\mathrm{rGO}(500)$ nanocomposite exhibited $86 \%$ degradation of rhodamine $\mathrm{B}$ dye and generated almost four times higher $\mathrm{H}_{2}$ via photocatalytic water splitting compared to commercially available P25 titania nanoparticles. This promising photocatalytic ability of the $\mathrm{Fe} / \mathrm{MgO}-\mathrm{rGO}(500)$ nanocomposite can be attributed to the improved morphological and surface features due to heat treatment at inert atmosphere as well as escalated charge carrier separation with increased light absorption capacity imputed to rGO incorporation.
\end{abstract}

\section{INTRODUCTION}

With the industrial revolution and an increase in the world population, the consistent growth in energy consumption, coupled with high pollution levels, has sparked tremendous research interest in alternative and renewable energy fuels [14. Solar energy is considered as a potential alternative energy source due to its abundance and sustainability. The efficient conversion of solar energy into chemical fuel is the ultimate challenge in confronting the energy crisis of today's world. Nowadays, the production of $\mathrm{H}_{2}$ through photocatalytic water splitting [5, 6] using solar energy is gaining sincere attention in the scientific community because they are simple, efficient and have significant potential for future development [7-10]. Owing to its low cost and environmentally friendly nature, hydrogen has emerged as the most feasible substitute for traditional fossil fuels as a green and efficient energy source with high storage capacity 11-15. Though at present, renewable energy contributes only $\sim 5 \%$ of commercial hydrogen production mainly through water electrolysis [16, the remaining $\sim 95 \%$ hydrogen is primarily generated from fossil fuels [17 which is neither cost-effective nor ecofriendly. Therefore, the development of efficient and cost-effective photocatalysts using renewable sources re-

* Email address: mabasith@phy.buet.ac.bd mains challenging. On the other hand, photodegradation using photocatalysts for environmental remediation has been recognized as an effective approach for converting hazardous industrial contaminants into non-toxic byproducts 18 20. In this context, several quantified photocatalysts, including $\mathrm{TiO}_{2}, \mathrm{ZnO}, \mathrm{CdS}$, $\mathrm{SrTiO}_{3}, \mathrm{CdS} / \mathrm{TiO}_{2} / \mathrm{Pt}$, and $\mathrm{TiO}_{2} / \mathrm{Ag}_{2} \mathrm{O}$, have been widely used [21 26]. Unfortunately, these existing photocatalysts suffer from limitations such as large band gap and quick recombination of $\mathrm{e}^{-}-\mathrm{h}^{+}$pairs, limiting their photocatalytic performance and solar energy utilization efficiency.

Magnesium oxide $(\mathrm{MgO})$ with high surface reactivity, extensive absorption capacity, and ease of production has been used recently for various applications, including catalysis, ceramics, waste-water remediation, anti-bacterial agents, and so on [27 29]. However, due to its large band gap energy and fast charge carrier recombination, bare $\mathrm{MgO}$ has negligibly lower photocatalytic performance [30]. These issues were resolved by adding low concentrations of transition metal ions at the conducting $\mathrm{MgO}$ interface, which prevents the formation of recombination centers for photo-generated $\mathrm{e}^{-}-\mathrm{h}^{+}$pairs 31. Among transition metal ions, iron (Fe) has a high transition ability and can trap multiple types of electron-hole pairs [32 34]. Thus incorporating $\mathrm{Fe}$ on $\mathrm{MgO}$ may improve the separation of the maximum number of electrons and holes, thereby avoiding recombination 35. In recent years, graphene, a two-dimensional (2D) network of hexagonally struc- 
tured $\mathrm{sp}_{2}$-hybridized carbon atoms, has sparked significant research interest in various energy adaptation applications as well as in the field of photocatalysis 36 38. The importance of graphene is attributed to its excellent charge carrier mobility, electrical conductivity, high specific surface area and superior chemical stability 39, 40. Graphene has two oxidative derivatives, between which reduced graphene oxide (rGO) demonstrates enhanced photocatalytic activity compared to graphene oxide (GO) when they are being tailored as supporting material to make a composite with photocatalysts 41, 42. The oxygen components over a pure GO surface may give a reverse action against its high electron conductivity, turning GO into an insulator [43, 44]. Several attempts have been adopted to synthesize pure graphene by reducing oxygen epoxy; among them, thermal treatment at inert atmosphere has been considered to be quite promising for producing high strength reduced graphene oxide by eliminating oxygen-containing functional groups from the surface of GO [45. Besides, thermal treatments may significantly modify the properties of photocatalysts since they have a notable impact on the physicochemical characteristics of the respective materials [46, 47].

Motivated by manifestations mentioned above, in this investigation, a simple hydrothermal route has been adopted for the synthesis of rGO supported $\mathrm{Fe} / \mathrm{MgO}$ nanocomposites followed by heat treatment at different temperatures at Argon (Ar) atmosphere. Several extensive studies have been carried out to synthesize nanoscale $\mathrm{MgO}$ powders using different synthesis techniques, such as solid state, sol-gel, chemical precipitation method, etc 48 50. Among various methods, the hydrothermal technique is regarded as one of the most successful approaches to obtain the desired structures with high phase purity and uniform size distribution with an additional advantage of being low cost [51]. According to our acknowledgement, here, for the first time, we report the application of hydrothermally synthesized $\mathrm{Fe} / \mathrm{MgO}-\mathrm{rGO}$ nanocomposite photocatalysts on wastewater remediation and generation of $\mathrm{H}_{2}$ through water splitting. Furthermore, the influence of heat treatment on the structure, morphology as well as the catalytic properties of $\mathrm{Fe} / \mathrm{MgO}-\mathrm{rGO}$ nanocomposites has also been explored. The photocatalytic performance of widely used Degussa titania (P25) nanoparticles has also been studied under similar experimental conditions for comparative analysis. It has been observed that $\mathrm{Fe} / \mathrm{MgO}-\mathrm{rGO}$ after heat treatment at 500 ${ }^{\circ} \mathrm{C}$ at $\mathrm{Ar}$ atmosphere demonstrated higher potential in $\mathrm{H}_{2}$ production via solar driven water splitting compared to other synthesized nanocomposites and P25 nanoparticles. In most of the previous investigations [52, 53], the photocatalytic performance of rGO based composites have been observed to be improved either by addition of $\mathrm{H}_{2} \mathrm{O}_{2}$ doses in dye and photocatalyst mix- ture, or by enhancing the power of light irradiation and controlling the $\mathrm{pH}$ of the solution, etc. However, in this investigation, $\mathrm{Fe} / \mathrm{MgO}-\mathrm{rGO}(500)$ nanocomposite has demonstrated satisfactory performance in $\mathrm{RhB}$ degradation and $\mathrm{H}_{2}$ evolution without using any additional reagents or external energy input and in neutral $\mathrm{pH}$ condition. We anticipate that this unique property might distinguish our synthesized composite from those reported by others. Finally, a plausible reaction mechanism for the profound photocatalytic activities of $\mathrm{Fe} / \mathrm{MgO}-\mathrm{rGO}(500)$ has been suggested.

\section{MATERIALS AND METHODS}

\section{A. Materials}

The chemical reagents used were analytical grade Manganese nitrate hexahydrate $\left[\mathrm{Mg}\left(\mathrm{NO}_{3}\right)_{3} \cdot 6 \mathrm{H}_{2} \mathrm{O}\right]$, Ferric nitrate nonahydrate $\left[\mathrm{Fe}\left(\mathrm{NO}_{3}\right)_{3} \cdot 9 \mathrm{H}_{2} \mathrm{O}\right]$, Graphite flakes, Sodium nitrate $\left[\mathrm{NaNO}_{3}\right]$, Sodium hydroxide $[\mathrm{NaOH}]$, Potassium permanganate $\left[\mathrm{KMnO}_{4}\right]$, Sulfuric acid $\left[\mathrm{H}_{2} \mathrm{SO}_{4}\right]$, Hydrochloric acid $[\mathrm{HCl}]$ and Hydrogen peroxide $\left[\mathrm{H}_{2} \mathrm{O}_{2}\right]$. All the reagents were manufactured by Sigma-Aldrich, Germany.

\section{B. Sample preparation}

\section{Synthesis of $\mathrm{Fe} / \mathrm{MgO}$ nanocomposites}

$\mathrm{Fe} / \mathrm{MgO}$ nanocomposites were synthesized by adopting a facile and low-cost hydrothermal technique [51. The first step was the synthesis of $\mathrm{MgO}$ nanoparticles, for which $1 \mathrm{mmol} \mathrm{Mg}\left(\mathrm{NO}_{3}\right)_{3} \cdot 6 \mathrm{H}_{2} \mathrm{O}$ were dissolved in 50 $\mathrm{ml}$ of $5 \mathrm{M} \mathrm{NaOH}$ solution and magnetically stirred for about 4 hours to form a homogeneous mixture. The solution was then transferred into a Teflon-lined autoclave and heated at $180{ }^{\circ} \mathrm{C}$ for 12 hours. The suspension was allowed to cool down to room temperature naturally. Afterwards, the final products were washed several times with deionized water and ethanol followed by centrifugation, and dried in the oven for 10 hours at $100{ }^{\circ} \mathrm{C}$. In the next step for incorporating $\mathrm{Fe}$ on $\mathrm{MgO}$ nanoparticles, $1 \mathrm{mmol} \mathrm{Mg}\left(\mathrm{NO}_{3}\right)_{3} \cdot 6 \mathrm{H}_{2} \mathrm{O}$ and $0.03 \mathrm{mmol}$ $\mathrm{Fe}\left(\mathrm{NO}_{3}\right)_{3} .9 \mathrm{H}_{2} \mathrm{O}$ were dissolved in $50 \mathrm{ml}$ of $5 \mathrm{M} \mathrm{NaOH}$ solution and the rest of the procedure was similar to that described earlier. After the hydrothermal process, both $\mathrm{MgO}$ and $\mathrm{Fe} / \mathrm{MgO}$ were treated at various temperatures at $\mathrm{Ar}$ atmosphere for further characterization. 


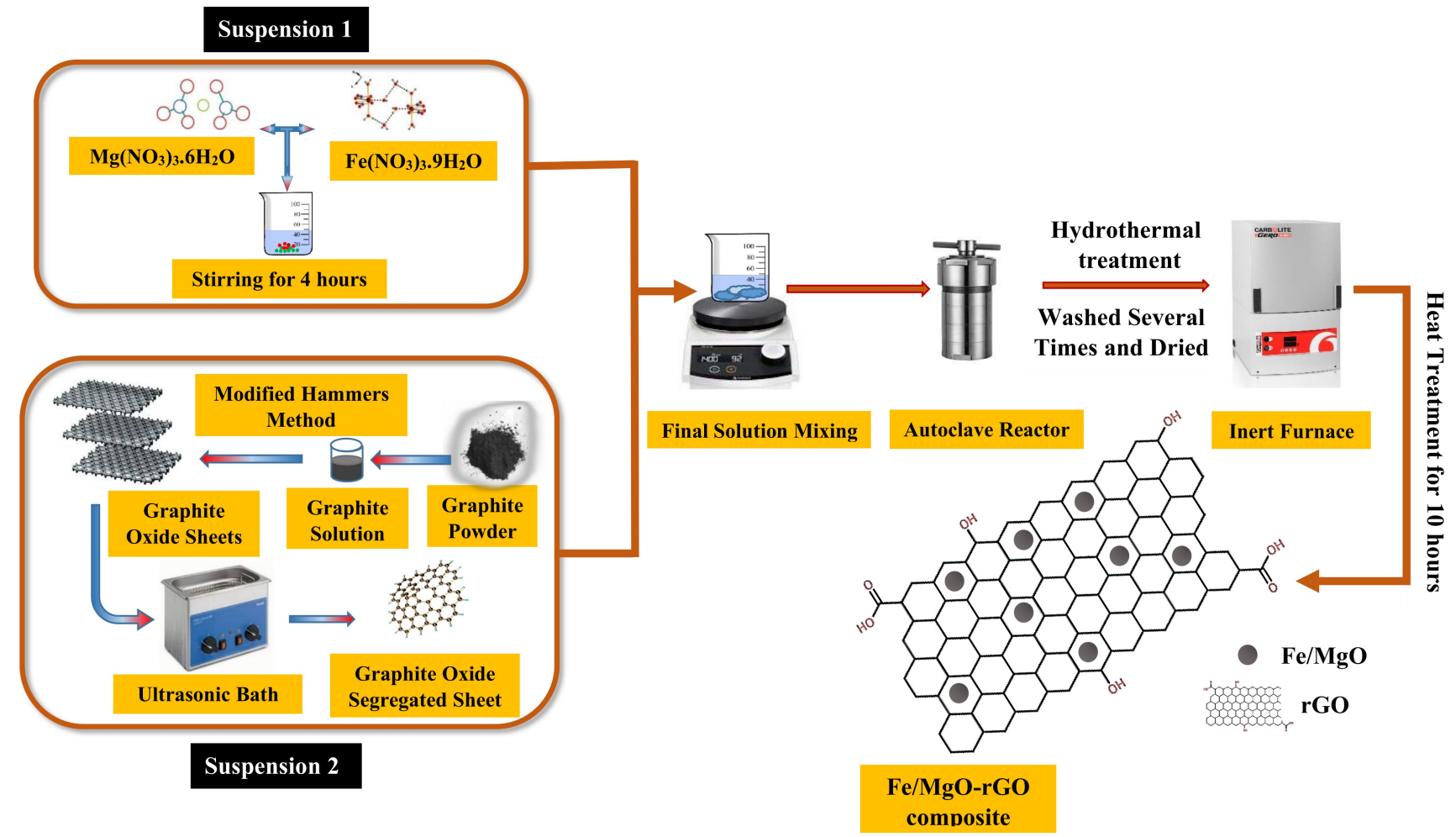

Figure 1. A schematic diagram of the synthesis scheme for $\mathrm{rGO}$ supported $\mathrm{Fe} / \mathrm{MgO}$ nanocomposites

\section{Synthesis of $\mathrm{Fe} / \mathrm{MgO}-\mathrm{rGO}$ nanocomposites}

Initially, $1 \mathrm{mmol} \mathrm{Mg}\left(\mathrm{NO}_{3}\right)_{3} \cdot 6 \mathrm{H}_{2} \mathrm{O}$ and $0.03 \mathrm{mmol}$ $\mathrm{Fe}\left(\mathrm{NO}_{3}\right)_{3} \cdot 9 \mathrm{H}_{2} \mathrm{O}$ were dissolved in $50 \mathrm{ml}$ of $5 \mathrm{M} \mathrm{NaOH}$ solution and stirred for 4 hours to get suspension I. In the next step, graphite oxide, prepared by modified Hummer's method [54], was sonicated for 2 hours in DI water to obtain graphene oxide (GO). Then $10 \mathrm{mg}$ of GO was dispersed in $10 \mathrm{ml}$ DI water to make suspension II . The suspension I and II were combined and stirred for an additional 1 hour. The mixture was then transferred into a Teflon-lined autoclave and heated at $180{ }^{\circ} \mathrm{C}$ for 12 hours. The hydrothermally synthesized products were washed and dried, and we have obtained the final composites after heat treatment of the dried products at 400 and $500{ }^{\circ} \mathrm{C}$ at $\mathrm{Ar}$ atmosphere. A schematic representation of the synthesis process has been depicted in Fig. 1.

\section{Characterization techniques}

The Crystalline structure and phase purity of the samples were characterized by the powder X-ray diffraction (XRD) spectra using a diffractometer (PANalytical Empyrean, UK; $\mathrm{Cu}-\mathrm{K}_{\alpha}, \lambda=1.5418 \AA$ ). Additionally, the Rietveld refinement approach was conducted for de- tailed analysis of the experimentally acquired XRD data using FullProf Suite Software [51]. The surface morphology were investigated from field emission scanning electron microscopy (FESEM) imaging along with the energy dispersive X-ray (EDX) analysis using a scanning electron microscope (XL30SFEG; Philips, Netherlands) and transmission electron microscopy (TEM) (Talos F200X; Thermo fisher scientific, USA) at an operating voltage of $200 \mathrm{kV}$. With an aim to observe the optical properties, the absorption spectra of the as-synthesized samples were investigated in the range of 200-600 nm using a UV-visible spectrophotometer (UV-2600; Shimadzu, Japan). Steady-state photoluminescence (PL) analysis was carried out using a Spectro Fluorophotometer (RF-6000; Shimadzu, Japan) to study the rate of photoinduced electron-hole recombination during the photocatalytic process [2].

\section{Photocatalytic degradation of dye}

The photocatalytic performance of the synthesized nanocomposites was assessed by monitoring the degradation of rhodamine $\mathrm{B}(\mathrm{RhB})$ dye in DI (deionized) water solution without the presence of any sacrificial agents. A 500W Xe lamp (Hamamatsu Photonics, Japan) having irradiance value of $100 \mathrm{~mW} \mathrm{~cm}^{-2}$ was 
used as a solar simulator 11. For each trial, $80 \mathrm{mg}$ of photocatalyst powder was dissolved in $15 \mathrm{mg} / \mathrm{L}$ of RhB solution. Prior to irradiation, the solution was magnetically stirred in the dark for 60 minutes to attain an adsorption equilibrium of $\mathrm{RhB}$ on the surface of the photocatalysts. After the lamp was turned on, $4 \mathrm{ml}$ of the solutions were extracted at 1 hour intervals and centrifuged to filter out the catalyst particles. The absorbance of the solution at a specific wavelength was measured using a UV-vis spectrophotometer to investigate the changes in $\mathrm{RhB}$ concentration caused by solar irradiation. The photodegradation process was repeated four times under identical experimental procedures to check the stability and reusability of the photocatalysts.

\section{E. Photocatalytic hydrogen evolution}

Photocatalytic hydrogen evolution experiment was conducted in a slurry type reactor, where $20 \mathrm{mg}$ of photocatalyst were mixed with $30 \mathrm{ml}$ DI water and kept under magnetic stirring before being illuminated by a 500W Hg-Xe lamp. Meanwhile, the system was purged with argon gas for 30 minutes to ensure an inert atmosphere for the splitting process. The evolved hydrogen $\left(\mathrm{H}_{2}\right)$ was extracted at one-hour intervals under illumination, then analyzed and quantified using the GC (Shimadzu, Japan) device equipped with the thermal conductance detector (TCD) and gas analyzer. The GC programming was reverse polarized in order to attain hydrogen peaks in the upward direction to allow a comparative analysis with the peak intensities of the various gases produced [11].

\section{RESULTS AND DISCUSSIONS}

\section{A. Structural characterization}

\section{Crystal structure}

The XRD patterns of $\mathrm{GO}, \quad \mathrm{Mg}(\mathrm{OH})_{2}$ and $\mathrm{Fe} / \mathrm{Mg}(\mathrm{OH})_{2}-\mathrm{GO}$ are shown in ESI (electronic supporting information) Fig. S1. The preparation of GO was confirmed from the characteristic peak (002) at Bragg position around $12 \vartheta$ [55], as shown in ESI Fig. S1(a). During the preparation of $\mathrm{MgO}$ following the hydrothermal method, hexagonal $\mathrm{Mg}(\mathrm{OH})_{2}$ were formed at $180{ }^{\circ} \mathrm{C}$ temperature by redox reactions [56]. Fig. S1(b) and (c) inserted in ESI demonstrate that the incorporation of $\mathrm{Fe}$ and $\mathrm{GO}$ into $\mathrm{MgO}$ during hydrothermal treatment resulted in the formation of $\mathrm{Fe} / \mathrm{Mg}(\mathrm{OH})_{2}-\mathrm{GO}$ at the same temperature. In the XRD pattern of $\mathrm{Fe} / \mathrm{Mg}(\mathrm{OH})_{2}-\mathrm{GO}$, we observe a peak for GO which indicates that the GO was not reduced. This can be attributed to the absence of any chemically reducing agent during hydrothermal preparation.

The Rietveld refinement method was used for detailed structural analysis of the samples after heat treatment at Ar atmosphere. Fig. 2(a), (b), (c), and (d) display the Rietveld refined powder XRD patterns of synthesized materials after heat treatment at $\mathrm{Ar}$ atmosphere. $\mathrm{MgO}$ and $\mathrm{Fe} / \mathrm{MgO}$ nanoparticles heated at $500{ }^{\circ} \mathrm{C}$ are represented by $\mathrm{MgO}(500)$ and $\mathrm{Fe} / \mathrm{MgO}(500)$, and $\mathrm{Fe} / \mathrm{MgO}-\mathrm{rGO}$ nanocomposites heated at 400 , and $500{ }^{\circ} \mathrm{C}$ are represented by $\mathrm{Fe} / \mathrm{MgO}-$ $\mathrm{rGO}(400)$ and $\mathrm{Fe} / \mathrm{MgO}-\mathrm{rGO}(500)$, respectively. It is confirmed that following the heat treatment at $500{ }^{\circ} \mathrm{C}$ at $\mathrm{Ar}$ atmosphere, the synthesized hexagonal structured $\mathrm{Mg}(\mathrm{OH})_{2}$ was converted into cubic $\mathrm{MgO}$ which is consistent with a previous investigation [56].

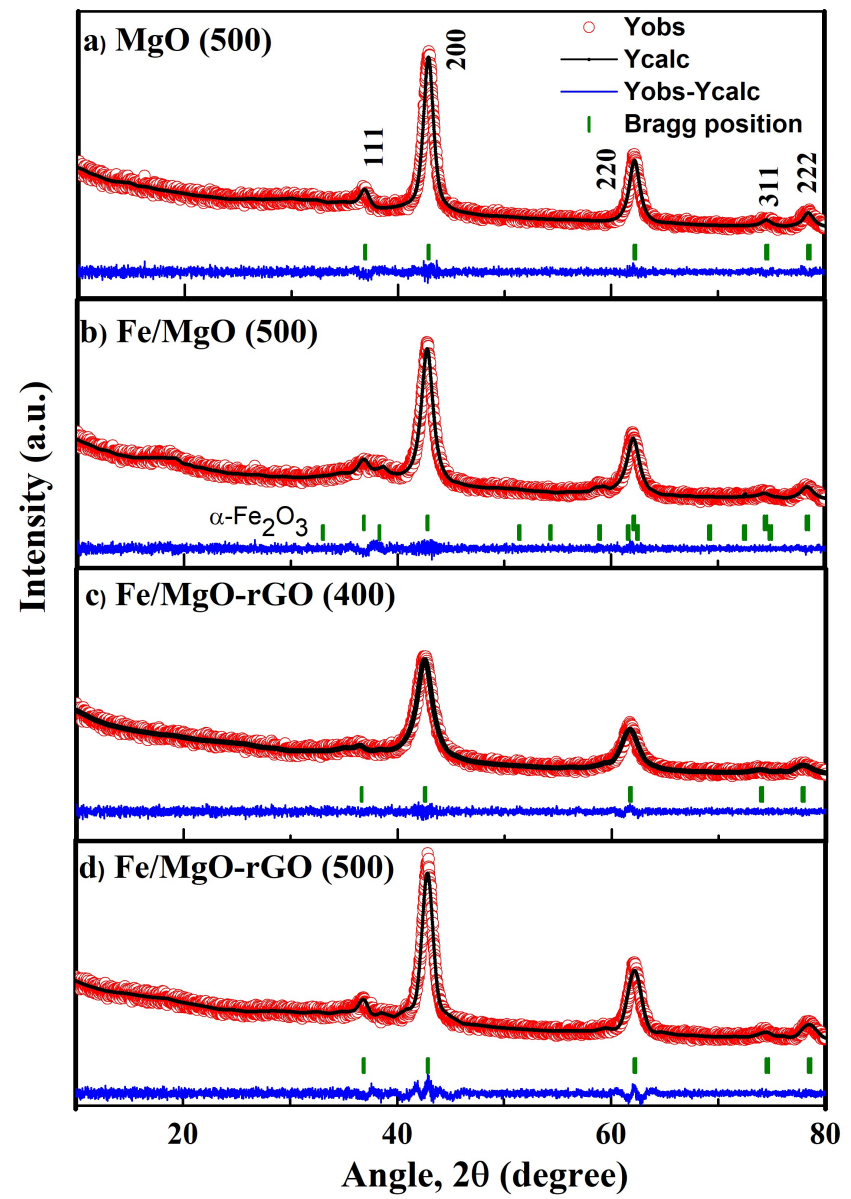

Figure 2. XRD patterns of (a) $\mathrm{MgO}(500)$, (b) $\mathrm{Fe} / \mathrm{MgO}(500)$ nanoparticles, and (c) Fe/MgO-rGO(400), (d) Fe/MgO$\mathrm{rGO}(500)$ nanocomposites after heat treatment at Ar atmosphere

Moreover, it can be observed that all samples display characteristics diffraction peaks indexed at (111), 
(200), (220), (311) and (222) planes which are in good accordance with cubic $\mathrm{MgO}$ with $\mathrm{Fm}$-3m space group (JCPDS card no. 1-75-447 57]). Fig. 2(a) and (b) show that due to the incorporation of $\mathrm{Fe}$ in $\mathrm{MgO}(500)$ nanoparticles, the peak positions remained the same, which suggested that $\mathrm{Fe}$ did not alter $\mathrm{MgO}$ crystal structure and was suitably deposited on the surfaces of $\mathrm{MgO}$ 35. Though the presence of an additional iron oxide phase $\alpha-\mathrm{Fe}_{2} \mathrm{O}_{3}$ was observed in $\mathrm{Fe} / \mathrm{MgO}(500)$ samples (Fig. 2(b)) due to iron substitution, which was eliminated when GO was added into the sample and heated at inert atmosphere as shown in Fig. 2(c) 31.

Comparing the XRD patterns of ESI Fig. $\mathrm{S} 1(\mathrm{c})$ and Fig. 2(c), the formation of Fe/MgO-rGO is assured at $400{ }^{\circ} \mathrm{C}$ temperature with an absence of GO peak indicating the total reduction of GO. This is consistent with the reduction mechanism of GO by thermal deoxygenation, in which an increase in temperature facilitates the removal of oxygen-containing functional groups from GO [58, 59]. This also explains the disappearance of $\alpha-\mathrm{Fe}_{2} \mathrm{O}_{3}$ phase due to GO substitution. With the increased temperature at Ar atmosphere, slightly decreased peak broadening as well as an increase in peak intensities was observed (Fig. 2(c) and $(\mathrm{d}))$. This decreasing trend of peak broadening indicates the increase in particle size, suggesting agglomeration at a higher temperature [60, 61].

Table 1 presents different structural parameters along with constituent phases for as-synthesized samples. Notably, the calculated lattice parameters are well consistent with the values reported in the literature 62. The lattice parameters and volume corresponding to the $\mathrm{MgO}$ phase remain almost unaltered throughout the synthesis process, which confirmed that the crystal structure was not distorted. The refined and observed XRD patterns for the cubic $\mathrm{MgO}$ phase are in reasonable agreement according to the fitting parameters $\left(\mathrm{R}_{\mathrm{wp}}, \mathrm{R}_{\mathrm{p}}, \mathrm{R}_{\mathrm{Exp}}\right.$ and $\left.\chi^{2}\right)$ and atomic coordinates (ESI Table S1).

\section{Surface morphology}

The FESEM image in Fig. 3(a) demonstrates randomly aggregated, thin, crumpled sheets like structure of $\mathrm{GO}$ 55. In $\mathrm{Fe} / \mathrm{Mg}(\mathrm{OH})_{2}-\mathrm{GO}$ samples, without heat treatment (ESI Fig. S2(a)), numerous $\mathrm{Fe} / \mathrm{Mg}(\mathrm{OH})_{2}$ hexagons with different particle sizes were predominately observed to be grown and randomly distributed on the GO surface. Fig. 3(b), (c), and (d) represent the FESEM images of $\mathrm{Fe} / \mathrm{MgO}$ sample heated at 500 ${ }^{\circ} \mathrm{C}$ and $\mathrm{Fe} / \mathrm{MgO}-\mathrm{rGO}$ samples heated at 400 and 500 ${ }^{\circ} \mathrm{C}$ at $\mathrm{Ar}$ atmosphere, respectively. It can be seen that for $\mathrm{Fe} / \mathrm{MgO}-\mathrm{rGO}(400)$ sample, the surface are not homogeneous, and the particles growth is not up to the mark, which can be ascribed to the fact that hexagonal $\mathrm{Fe} / \mathrm{Mg}(\mathrm{OH})_{2}$ did not completely transformed into cubic $\mathrm{Fe} / \mathrm{MgO}$ at lower heating temperature $\left(400{ }^{\circ} \mathrm{C}\right)$. However, due to graphene incorporation, a large number of $\mathrm{Fe} / \mathrm{MgO}$ nanocrystallites nucleate and grow into fine seed particles at the early stage of hydrothermal treatment; with time, this is followed by the growth of $\mathrm{Fe} / \mathrm{MgO}$ nuclei [63, 64. Surprisingly, when composites are formed with rGO, such consumption of finer seed particles that lead to the growth of nuclei is interrupted due to steric blockage of seed particle transportation caused by the interpenetrating graphene networks 65. However, for $\mathrm{Fe} / \mathrm{MgO}-\mathrm{rGO}$ nanocomposite at 500 ${ }^{\circ} \mathrm{C}$ temperature, the particle size distribution seems to be more homogeneous than the samples treated at 400 ${ }^{\circ} \mathrm{C}$. For a further increase in temperature to $600{ }^{\circ} \mathrm{C}$, resulted in a significant amount of agglomeration 66, as can be observed in ESI Fig. S2(b). This result implies that $500{ }^{\circ} \mathrm{C}$ is the optimized Ar atmosphere required to form $\mathrm{Fe} / \mathrm{MgO}-\mathrm{rGO}$ nanocomposites with a higher degree of uniformity in shape and size. To get further insight into the morphology of the rGO supported $\mathrm{Fe} / \mathrm{MgO}$ nanocomposite at $500{ }^{\circ} \mathrm{C}$, TEM imaging was performed at various magnifications (Fig. 4). The TEM image, Fig. 4(a) clearly demonstrated the distribution of $\mathrm{Fe} / \mathrm{MgO}$ nanoparticles on rGO sheets. The higher magnification images, Fig. 4(b) and (c) confirmed the presence of graphene sheets. In Fig. 4(d) we have observed bright concentric rings in the selected area electron diffraction (SAED) pattern, which implied the polycrystalline nature of the synthesized nanocomposite.

\section{Elemental composition}

The compositions of the synthesized samples were identified utilizing EDX analysis. The experimental details in ESI Fig. S3 show that the desired elements C, $\mathrm{Mg}, \mathrm{O}$ and $\mathrm{Fe}$ are present in the synthesized samples, and no additional element was found. The EDX spectra were taken at three distinct positions, and the average atomic ratios of $\mathrm{Mg}, \mathrm{Fe}, \mathrm{O}$ and $\mathrm{C}$ were observed to be very close to nominal composition within the instrumental accuracy.

\section{B. Optical characterization}

\section{Optical band gap}

The optical properties of all the synthesized samples were studied using UV-visible diffuse reflectance spectroscopy (DRS) in the wavelength range of 200-600 nm. Fig. 5(a) demonstrates the room temperature 
Table I. Structural parameters of synthesized nanomaterials and nanocomposites.

\begin{tabular}{lllllll}
\hline Sample & Constituent & Crystallographic phase & Space group & $\mathrm{a}=\mathrm{b}(\AA)$ & $\mathrm{c}(\AA)$ & $\mathrm{V}\left(\AA^{3}\right)$ \\
\hline $\mathrm{MgO}(500)$ & $\mathrm{MgO}$ & Cubic & $F m-3 m$ & 4.220 & 4.220 & $75.176(0.005)$ \\
$\mathrm{Fe} / \mathrm{MgO}(500)$ & $\mathrm{MgO}$ & Cubic & $F m-3 m$ & 4.227 & 4.227 & $75.576(0.005)$ \\
& $\alpha-\mathrm{Fe}_{2} \mathrm{O}_{3}$ & Trigonal & $R-3 c$ & 5.430 & 5.429 & $138.649(0.001)$ \\
$\mathrm{Fe} / \mathrm{MgO}-\mathrm{rGO}(400)$ & $\mathrm{MgO}$ & Cubic & $F m-3 m$ & 4.250 & 4.250 & $76.794(0.008)$ \\
$\mathrm{Fe} / \mathrm{MgO}-\mathrm{rGO}(500)$ & $\mathrm{MgO}$ & Cubic & $F m-3 m$ & 4.221 & 4.221 & $75.243(0.005)$
\end{tabular}
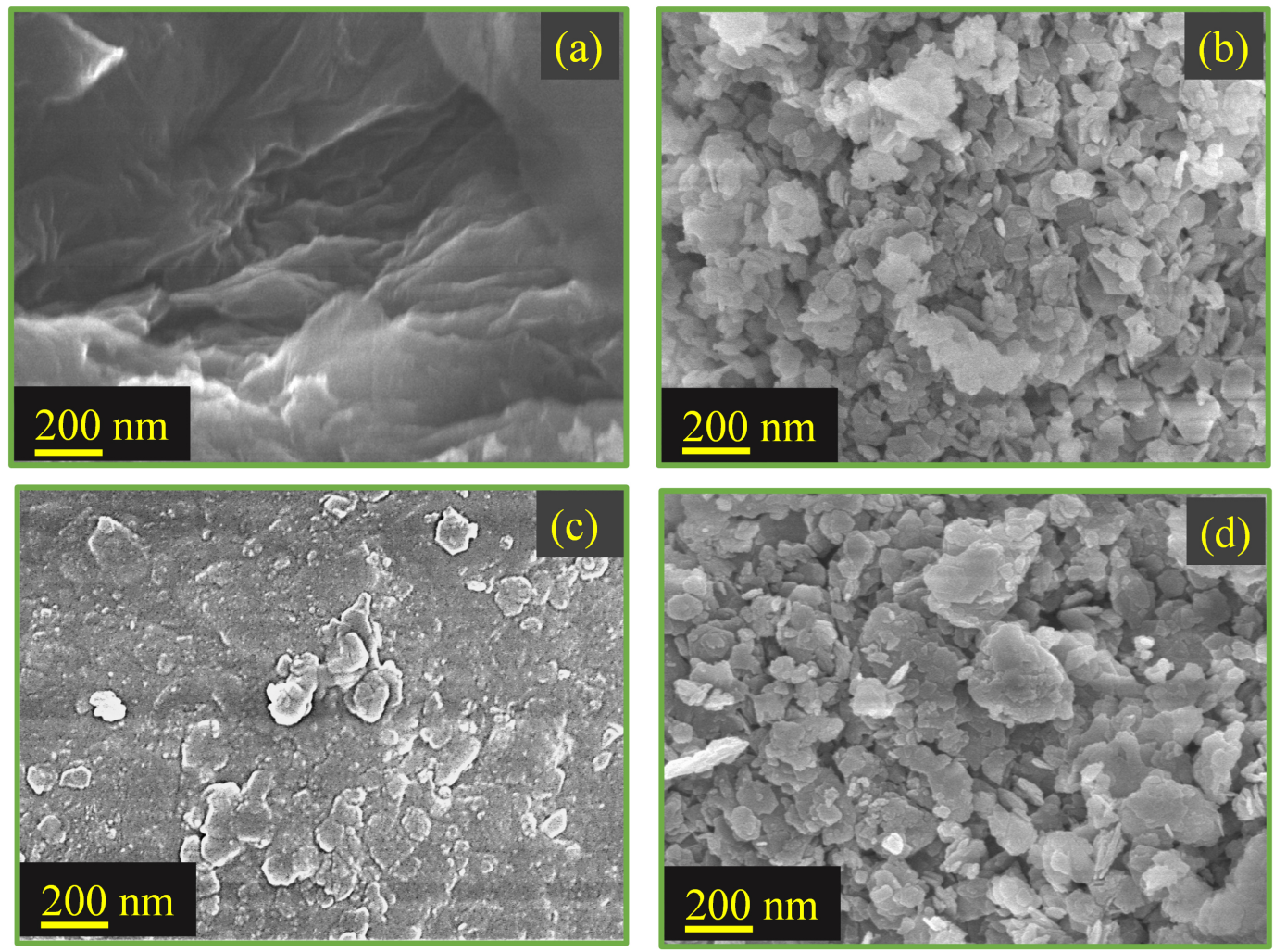

Figure 3. FESEM images of (a) GO, (b) $\mathrm{Fe} / \mathrm{MgO}(500)$, (c) Fe/MgO-rGO(400), and (d) Fe/MgO-rGO(500)

UV-visible absorption spectra of pure $\mathrm{MgO}, \mathrm{Fe} / \mathrm{MgO}$ nanoparticles and $\mathrm{Fe} / \mathrm{MgO}-\mathrm{rGO}$ nanocomposites after heat treatment at different reaction temperatures. All the samples exhibited continuous absorption across the $\mathrm{UV}$ region, at the same time, the addition of $\mathrm{rGO}$ showed an increase in the optical absorption compared to pure $\mathrm{MgO}$ and $\mathrm{Fe} / \mathrm{MgO}$ samples, indicating higher light absorption ability of the synthesized nanocomposites. Moreover, $\mathrm{MgO}$ nanoparticles exhibit a prominent absorption peak at $286 \mathrm{~nm}$, as shown in Fig. 5(a). In contrast all Fe-incorporated samples show a blue shift in the absorption peak, which can be attributed to the formation of donor energy levels in the actual band gap of $\mathrm{MgO}$.

The optical band gap $\mathrm{E}_{\mathrm{g}}$ of the samples were calculated using Tauc's relation [11]

$$
\mathrm{F}(\mathrm{R}) \times \mathrm{h} \nu=\mathrm{A}\left(\mathrm{h} \nu-\mathrm{E}_{\mathrm{g}}\right)^{\mathrm{n}}
$$

where $\mathrm{h} \nu, \mathrm{A}$ and $\mathrm{E}_{\mathrm{g}}$ denote the energy of the photon, proportionality constant and optical band gap, respectively and $F(R)$ is a parameter calculated from DRS 

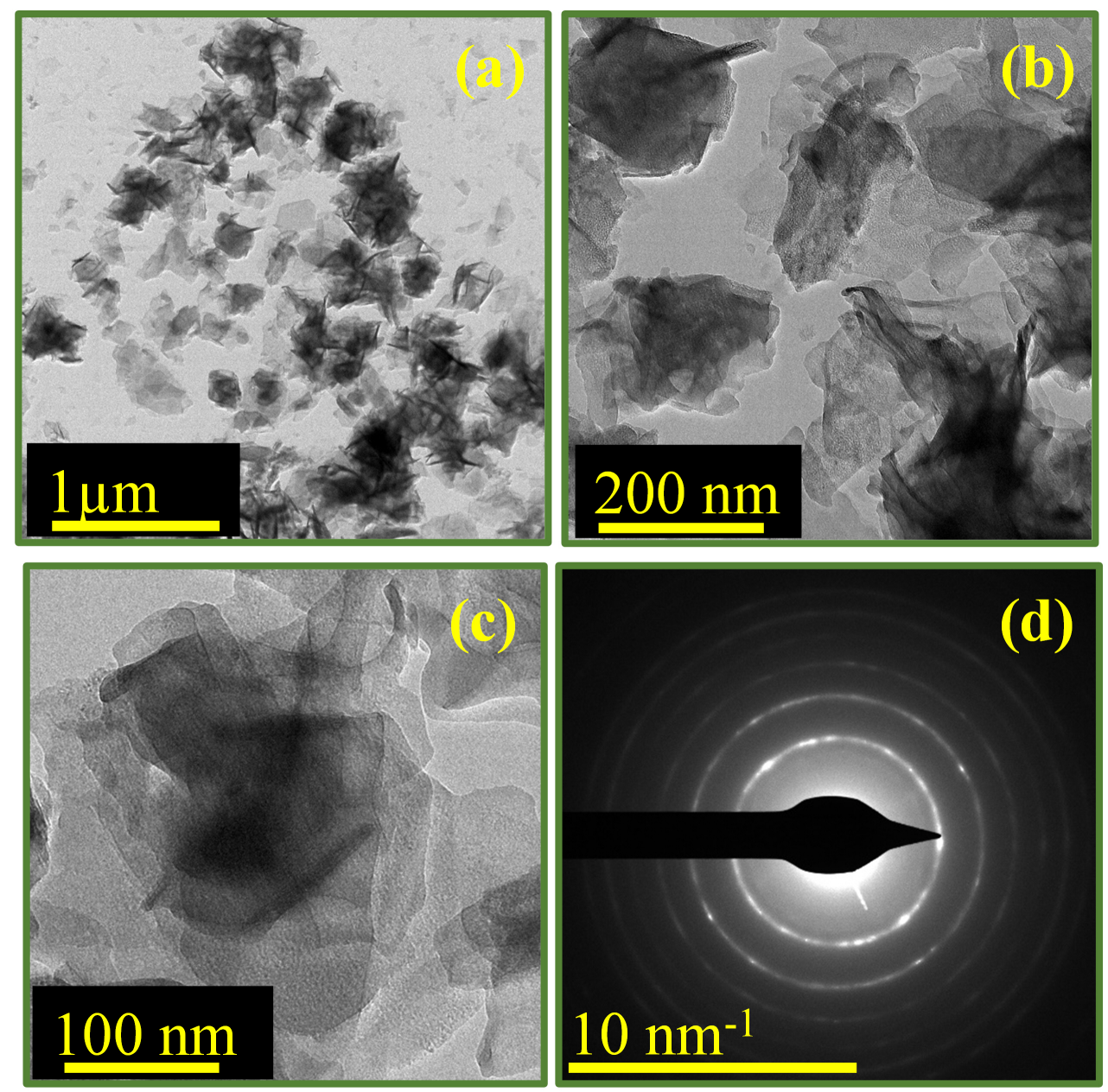

Figure 4. TEM images (a-c), and SAED pattern (d) of Fe/MgO-rGO(500) nanocomposite

by Kubelka-Munk function [51. From Fig. 5(b), the band gap energy was determined by extrapolating the straight-line portion to the abscissa at zero absorption co-efficient. The band gap of $\mathrm{MgO}$ is found to be $3.9 \mathrm{eV}$ which has been reduced to $3.3 \mathrm{eV}$ when Fe was incorporated into $\mathrm{MgO}$. Incorporation of $\mathrm{rGO}$ suppressed the crystal growth, resulting in smaller particle size and the band gap energy of $\mathrm{Fe} / \mathrm{MgO}-\mathrm{rGO}$ (400) nanocomposite was reduced to $2.78 \mathrm{eV}$ [55]. As the temperature rises from 400 to $500{ }^{\circ} \mathrm{C}$, there is an increase in band gap from 2.78 to $3.0 \mathrm{eV}$ due to quantum confinement effect 67. Another reason is that extremely high temperature promotes the generation of strong bonds between the crystallites, leading to the agglomeration of particles 68. Interatomic bonds are tightened and high energy is required to break a bond, and move an electron to the conduction band.

\section{Photoluminescence (PL) spectra at steady-state}

A photocatalyst must possess the ability to inhibit the electron-hole pair recombination efficiently. To study this property, we have conducted the PL analysis of our samples for an excitation wavelength of $200 \mathrm{~nm}$ as represented in ESI Fig. S4. The optical band gaps from the position of the PL peaks are observed to be 3.40 , 2.69 and $3.03 \mathrm{eV}$ for $\mathrm{Fe} / \mathrm{MgO}(500), \mathrm{Fe} / \mathrm{MgO}-\mathrm{rGO}(400)$ and $\mathrm{Fe} / \mathrm{MgO}-\mathrm{rGO}(500)$ samples, respectively. These values are in accordance with the band gaps obtained from UV-visible spectroscopy (Fig. 5(b)). Notably, the peak intensity of both rGO supported samples are lower than $\mathrm{Fe} / \mathrm{MgO}$ samples, which suggests that the separation of photogenerated electron-hole pairs can be facilitated through rGO incorporation. This result is also consistent with our previous band gap estimation by DRS, where the band gaps of all rGO assisted nanocomposites are smaller than those of $\mathrm{Fe} / \mathrm{MgO}$. 

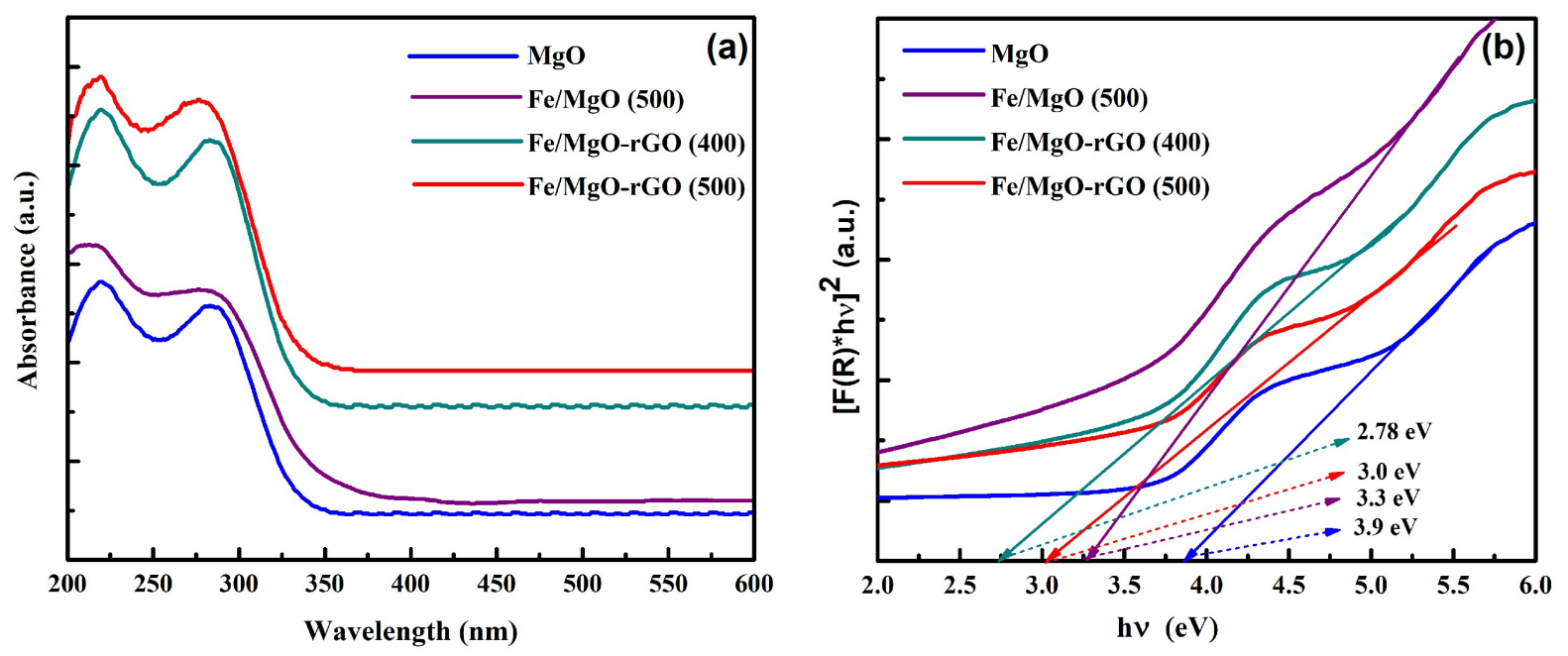

Figure 5. (a) UV-visible absorbance and (b) Tauc plots for band gap estimation for $\mathrm{MgO}, \mathrm{Fe} / \mathrm{MgO}$ nanoparticles heated at $500{ }^{\circ} \mathrm{C}$ and $\mathrm{Fe} / \mathrm{MgO}-\mathrm{rGO}$ nanocomposites heated at 400 and $500{ }^{\circ} \mathrm{C}$ at $\mathrm{Ar}$ atmosphere

Moreover, for $\mathrm{Fe} / \mathrm{MgO}-\mathrm{rGO}(500)$, the peak intensity is lowest as compared to other samples, which imply the successful separation and transfer of photogenerated charge carriers. As a result, the photocatalytic activity of this nanocomposite under solar irradiation increases by inhibiting electron-hole pair recombination [69]. The outcome of our experiment is also in good agreement with previous reports, where PL emission is observed to be quenched due to rGO substitution [70, 71 ]

\section{Photocatalytic degradation of rhodamine B $(\mathrm{RhB})$ dye}

To evaluate the photocatalytic performance of the assynthesized materials, at first, a blank test was conducted without any catalyst. RhB did not show significant degradation for four hours indicating the selfdegradation ability of RhB is extremely low. After that, the catalyst samples were blended with $\mathrm{RhB}$ solution and kept in the dark under constant magnetic stirring in order to achieve adsorption equilibrium. In Fig. 6(a) and (b), we have presented the time-dependent UVvisible absorbance spectra of $\mathrm{RhB}$ at one-hour intervals in the presence of $\mathrm{Fe} / \mathrm{MgO}-\mathrm{rGO}(400)$ and $\mathrm{Fe} / \mathrm{MgO}-$ rGO(500) photocatalysts. The decrease in absorbance peak as irradiation time extends, indicates the decomposition of $\mathrm{RhB}$ under solar irradiation. It was observed that incorporation of $\mathrm{rGO}$, and heat treatment has resulted in a significant improvement in degradation efficiency of the nanocomposites and the maximum degradation of $\mathrm{RhB}$ was observed at $500{ }^{\circ} \mathrm{C}$ at $\mathrm{Ar}$ at- mosphere. This result may be attributed to the relationship between the stability of the crystal structure and the effectiveness of reduced graphene oxide for solar light absorption 68.

The degradation efficiency as well as degradation rate were calculated by using the following equation

$$
\text { Photocatalytic degradation }(\%)=\frac{\mathrm{C}_{0}-\mathrm{C}}{\mathrm{C}_{0}} \times 100
$$

Fig. 6(c) demonstrates the degradation characteristics of $\mathrm{RhB}$ as a function of solar irradiation time in the presence of as-synthesized $\mathrm{MgO}, \mathrm{Fe} / \mathrm{MgO}(500)$, $\mathrm{Fe} / \mathrm{MgO}-\mathrm{rGO}(400)$ and $\mathrm{Fe} / \mathrm{MgO}-\mathrm{rGO}(500)$ photocatalysts as well as commercially available Degussa $\mathrm{TiO}_{2}$ (P25) nanoparticles for comparison. $\mathrm{C}_{0}$ and $\mathrm{C}$ represent the primary and retained concentrations of $\mathrm{RhB}$ in the solution, respectively. The degradation efficiency of pure $\mathrm{MgO}, \mathrm{Fe} / \mathrm{MgO}(500)$, Fe/MgO-rGO(400) and $\mathrm{Fe} / \mathrm{MgO}-\mathrm{rGO}(500)$ was $\sim 25 \%, \sim 42 \%, \sim 80 \%$ and $\sim 86 \%$, respectively. The photodegradation curve of commercial titania (P25) was also plotted in Fig. 6(c) for comparison. Interestingly, the degradation percentage of all the samples except $\mathrm{MgO}$ is higher compared to P25. The large band gap and quick charge carrier recombination might be responsible for this poor degradation efficiency of $\mathrm{MgO}$. Due to the presence of Fe on $\mathrm{MgO}$, the band gap was reduced, the active surface of $\mathrm{MgO}$ was increased, and the RhB dye degradation efficiency was enhanced accordingly [33, 34. Moreover, for comparison we have also evaluated the photodegradation ability of $\mathrm{Fe}_{2} \mathrm{O}_{3}, \mathrm{Fe}_{2} \mathrm{O}_{3}-\mathrm{MgO}$, and $\mathrm{Fe}_{2} \mathrm{O}_{3}-\mathrm{rGO}$ samples for comparison. It was observed that under four hours of solar irradiation, the degradation efficiency was 

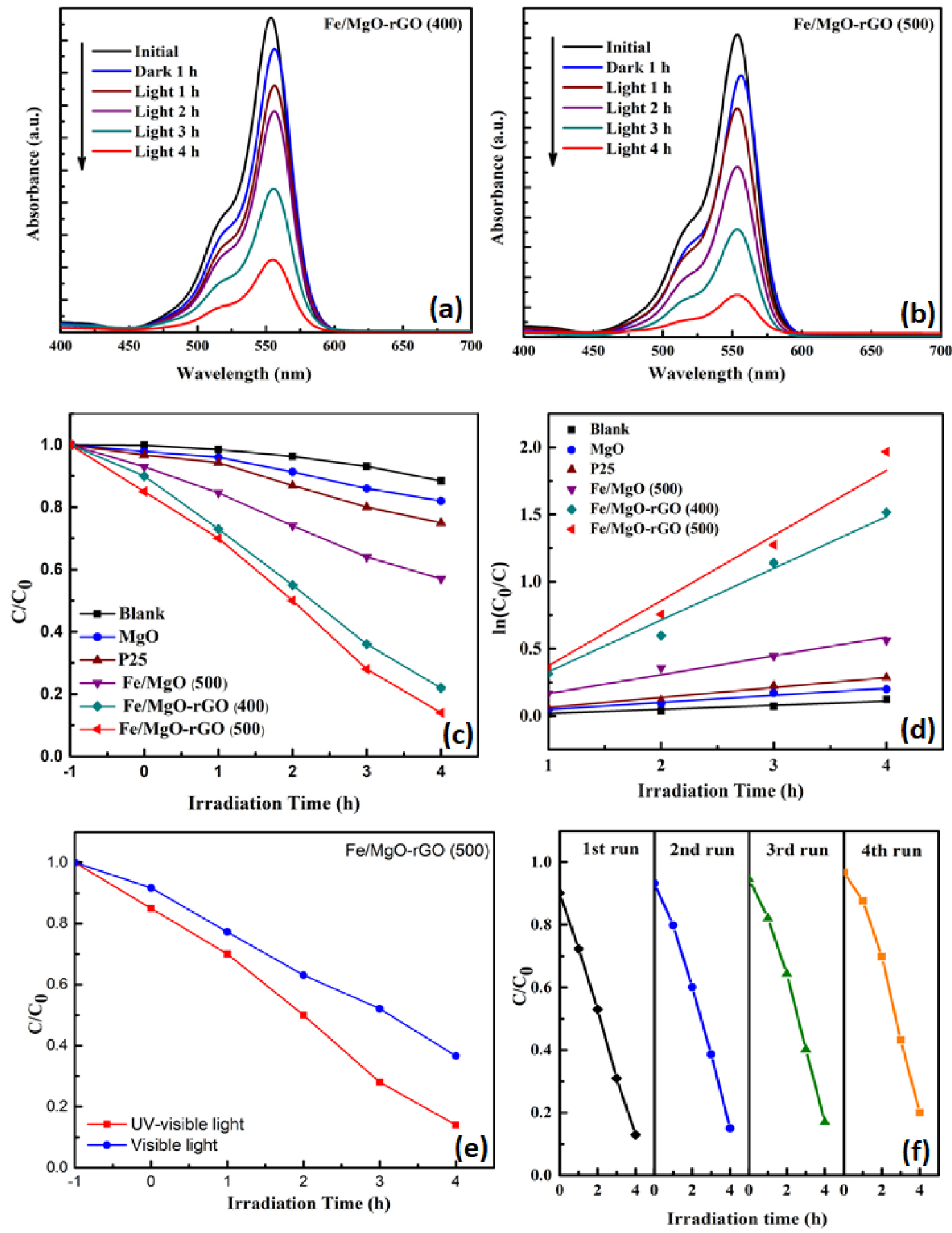

Figure 6. Spectral changes during the deterioration of RhB over (a) Fe/MgO-rGO(400), and (b) Fe/MgO-rGO(500) nanocomposites under solar irradiation;(c) RhB concentration change as a function of irradiation time, (d) First-order kinetic plots for the photodegradation of $\mathrm{RhB}$, (e) Change in $\mathrm{RhB}$ concentration under different wavelength conditions, and (f) Recyclability test of $\mathrm{Fe} / \mathrm{MgO}-\mathrm{rGO}(500)$ for four successive runs

$\sim 38 \%, \sim 43 \%$, and $\sim 52 \%$ for the respective samples, which was significantly lower than that of $\mathrm{Fe} / \mathrm{MgO}-\mathrm{rGO}$ nanocomposites. The synthesis procedure of the abovementioned samples and the experimental findings of the photodegradation experiments have been attached in the supplementary (ESI Fig. S5). From these observations, it can be elucidated that the inclusion of rGO in $\mathrm{Fe} / \mathrm{MgO}-\mathrm{rGO}$ nanocomposite significantly improved 
their photocatalytic performance. The highest photocatalytic degradation efficiency of $\sim 86 \%$ was observed for $\mathrm{Fe} / \mathrm{MgO}-\mathrm{rGO}$ nanocomposite, which was heated at $500{ }^{\circ} \mathrm{C}$ at $\mathrm{Ar}$ atmosphere. We think that at optimum temperature of $500{ }^{\circ} \mathrm{C}$ maximum number of oxides were removed from GO and resulted in the successful migration of electrons from the conduction band (CB) of $\mathrm{Fe} / \mathrm{MgO}$ to rGO 72 . This migration inhibited electronhole pair recombination and resulted in an outstanding photocatalytic performance of $\mathrm{Fe} / \mathrm{MgO}-\mathrm{rGO}(500)$ nanocomposite [73. In addition, from the FTIR analysis of $\mathrm{Fe} / \mathrm{MgO}-\mathrm{rGO}(500)$ nanocomposite we can observe peaks at 1450 and $3390 \mathrm{~cm}^{-1}$, indexed to $-\mathrm{OH}$ and $\mathrm{H}-\mathrm{O}-\mathrm{H}$ vibration bonds, respectively (ESI Fig. S6). These oxygen-containing groups have an effective role in the photocatalytic activity of catalysts by generating more hydroxyl radicals to facilitate the photocatalytic process [72, 74].

We have incorporated the Pseudo first-order kinetics model to quantitatively study the kinetics of the photocatalytic degradation using the following equation [6]:

$$
\ln \left(\mathrm{C}_{0} / \mathrm{C}\right)=\mathrm{kt}
$$

Where $\mathrm{C}_{0}$ and $\mathrm{C}$ represent the same as previously stated, and $\mathrm{k}\left(\mathrm{min}^{-1}\right)$ is the pseudo-first order rate constant of photodegradation. The rate constant was calculated by using a linear fit to the plot of $\ln \left(\mathrm{C}_{0} / \mathrm{C}\right)$ versus irradiation time. Based on the results from Fig. 6(d), the highest degradation rate was observed for $\mathrm{Fe} / \mathrm{MgO}-\mathrm{rGO}(500)$ with a rate constant of $\mathrm{k}=7.072 \times 10^{-3} \mathrm{~min}^{-1}$, which is 2.86 times higher than that of $\mathrm{Fe} / \mathrm{MgO}\left(\mathrm{k}=2.479 \times 10^{-3} \mathrm{~min}^{-1}\right)$. Considering the degradation efficiency and rate constant, $\mathrm{Fe} / \mathrm{MgO}-$ rGO(500) can be regarded as a superior solar light driven photocatalyst to be used for environmental remediation purpose. The mechanism behind this profound performance of $\mathrm{Fe} / \mathrm{MgO}-\mathrm{rGO}(500)$ has been discussed subsequently.

Furthermore, to study the role of light with different wavelengths, the photodegradation ability of $\mathrm{Fe} / \mathrm{MgO}-\mathrm{rGO}(500)$ nanocomposite was also evaluated using a UV cut-off filter $(\lambda \geq 420 \mathrm{~nm})$ where the efficiency was obtained to be only $\sim 64 \%$ (Fig. $6(\mathrm{e})$ ) which is lower than that obtained under UV-visible irradiation. This result justifies our findings from optical characterizations, where continuous absorption across the $\mathrm{UV}$ region was exhibited by $\mathrm{Fe} / \mathrm{MgO}-\mathrm{rGO}$ composites.

\section{Photostability of $\mathrm{Fe} / \mathrm{MgO}-\mathrm{rGO}(500)$ nanocomposite}

The stability and re-usability of the $\mathrm{Fe} / \mathrm{MgO}$ rGO(500) nanocomposite has been checked, employing a recyclability test to validate their applicability

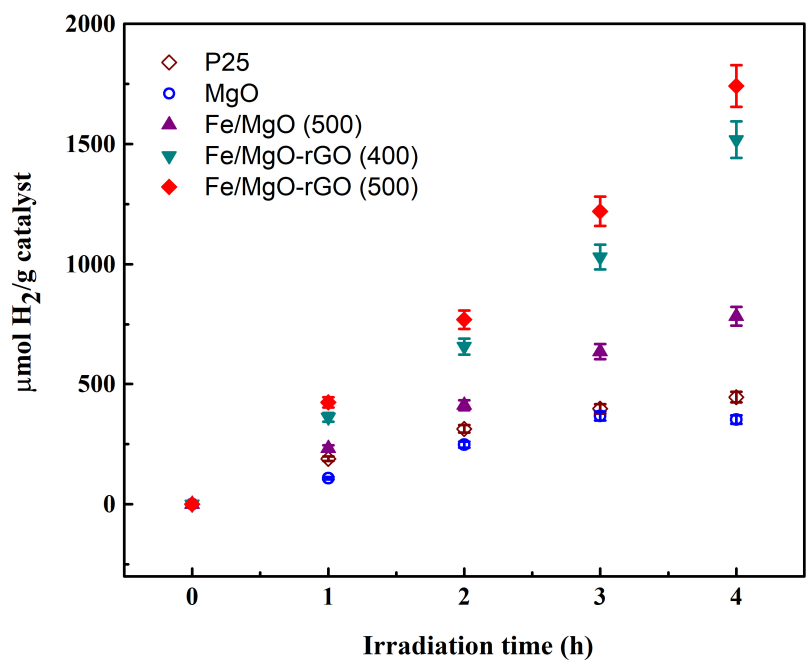

Figure 7. Amount of $\mathrm{H}_{2}$ evolved via water splitting with respect to irradiation time

in practical fields [51]. It has been observed from Fig. 6(f) that after four consecutive photo-degradation cycles, the change in dye degradation efficiency of the catalyst was trivial, which could be related to the loss in material during the recovery process. The outcome of this study anticipates the prospect of this material for repeated application in waste-water management and other photocatalytic purposes.

\section{Photocatalytic hydrogen generation}

We have evaluated the efficiency of the synthesized photocatalysts as a worthy candidate for hydrogen generation via water splitting under solar irradiation [11. Fig. 7 demonstrates the amount of $\mathrm{H}_{2}$ gas produced by our synthesized catalysts as a function of solar irradiation time. For comparison, the hydrogen generation under identical conditions by titania P25 nanoparticles was also included. The hydrogen production of commercially available P25 nanoparticles was observed to be $\sim 445 \mu \mathrm{mol} \mathrm{g}{ }^{-1}$. As shown in Fig. $7, \mathrm{Fe} / \mathrm{MgO}$ photocatalyst's hydrogen evolution is slightly higher than that of P25 nanoparticles. Notably, the rate of hydrogen production increased significantly when rGO was introduced into $\mathrm{Fe} / \mathrm{MgO}$, and it was observed that the total amount of $\mathrm{H}_{2}$ evolved under 4 hours of solar irradiation were $\sim 1517$ and $\sim 1741 \mu \mathrm{mol} \mathrm{g}^{-1}$ for the Fe/MgOrGO(400) and $\mathrm{Fe} / \mathrm{MgO}-\mathrm{rGO}(500)$ nanocomposites, respectively.

It is well established that Photocatalytic $\mathrm{H}_{2}$ generation mainly includes three basic steps: (1) absorption of photons by the photocatalyst to form electronhole pairs; (2) separation and migration of the photo- 
induced charges to different photocatalyst sites; and (3) reduction of water to evolve $\mathrm{H}_{2}$ on the surface of the photocatalyst by the photo-generated electrons. In our case, $\mathrm{Fe} / \mathrm{MgO}-\mathrm{rGO}(500)$ nanocomposite absorbed a significant amount of photons to produce electron-hole pairs due to its narrow band gap and graphene, with its high work function $(4.42 \mathrm{eV})$ and superior conductivity, played the crucial role by accepting photo-generated electrons and rapidly migrating these electrons through its $2 \mathrm{D}$ plane to reactive sites, which resulted in a significant amount of $\mathrm{H}_{2}$ evolution [75, 76]. For further insight, a comparative analysis between our experimental findings and some previous related investigations has been presented in Table 2. Noticeably, our Fe/MgOrGO(500) nanocomposite exhibited a comparatively increased $\mathrm{H}_{2}$ evolution rate (HER) than other rGO supported and $\mathrm{MgO}$ based nanocomposites. Additionally, in most cases, various sacrificial reagents were used as electron donors to enhance $\mathrm{H}_{2}$ generation rate. However, in this present investigation, we have obtained a notable result on solar hydrogen generation by water splitting without any additional reagent.

\section{E. Photocatalytic mechanism}

In order to gain a better perspective of the profound photocatalytic performance of $\mathrm{Fe} / \mathrm{MgO}-\mathrm{rGO}$ nanocomposites, a plausible mechanism for the photodegradation of RhB under solar illumination is proposed with the help of a schematic illustration (Fig. 8). The band edge positions were calculated using the Mulliken electronegativity method using the following equations 80

$$
\begin{gathered}
\mathrm{E}_{\mathrm{CB}}=\chi-\mathrm{E}_{\mathrm{c}}-\frac{1}{2} \mathrm{E}_{\mathrm{g}} \\
\mathrm{E}_{\mathrm{VB}}=\mathrm{E}_{\mathrm{CB}}+\mathrm{E}_{\mathrm{g}}
\end{gathered}
$$

where $\mathrm{E}_{\mathrm{CB}}$ and $\mathrm{E}_{\mathrm{VB}}$ are conduction and valence band edge potentials with respect to Normal Hydrogen Electrode (NHE) ; $\chi$ is the absolute electronegativity, expressed as the geometric mean of the absolute electronegativity of the constituent atoms; $\mathrm{E}_{\mathrm{g}}$ is the band gap of the sample and $\mathrm{E}_{\mathrm{c}}$ is the energy of free electrons on the hydrogen scale $(\sim 4.5 \mathrm{eV})$. It is well established that, along with optical band gap, CBM (conduction band minimum) and VBM (valance band maximum) play crucial roles in catalyzing the redox reactions in the electrolyte system. Efficient photocatalytic degradation ability of the nanocomposites can be better understood by analyzing the redox reactions in the electrolyte system that govern the degradation of RhB dye. For successful degradation of RhB under solar irradiation two redox reactions are particularly important. First, the photogenerated electron can react with the surface adsorbed oxygen (redox potential: $-0.16 \mathrm{eV}$ vs. NHE) to form $\cdot \mathrm{O}_{2}^{-}$radicals, which will further react with $\mathrm{RhB}$ to cause degradation. Second, the photogenerated holes can react with the $\mathrm{OH}^{-}$radicals, ionized from the water molecules to produce $\cdot \mathrm{OH}$ (redox potential: $2.38 \mathrm{eV}$ vs. $\mathrm{NHE}$ ). This $\cdot \mathrm{OH}$ can further oxidize the RhB molecules. Therefore, a photocatalyst needs to possess a $\mathrm{CBM}<-$ $0.16 \mathrm{eV}$ to drive the frst reaction and $\mathrm{VBM}>2.38 \mathrm{eV}$ to drive the second one efficiently 55 .

$\mathrm{CBM}$ and $\mathrm{VBM}$ for $\mathrm{MgO}$ has been determined to be -1.24 and $2.66 \mathrm{eV}$, respectively, which imply that $\mathrm{MgO}$ can perform the redox reactions of $\mathrm{RhB}$ degradation since it has fulfilled the above mentioned criteria. However, lower absorption of photons due to the large value of optical band gap in $\mathrm{MgO}$, resulted in poor photocatalytic activity. Introduction of iron $\mathrm{Fe}^{3+}$ ions into the $\mathrm{MgO}$ surface, effectively leads to band gap narrowing, creating a sub level above the valance band (VB) of $\mathrm{MgO}$. Under solar illumination, electrons in the $\mathrm{VB}$ of $\mathrm{MgO}$ can firstly transfer to Fe intermediate band through absorbing photons with longer wavelength, and these electrons then transfer from intermediate band to conduction band $(\mathrm{CB})$ leaving holes in the VB. Moreover, the $\mathrm{Fe}^{3+}$ ions can be reduced to $\mathrm{Fe}^{2+}$ ions by the photogenerated electrons during the photocatalysis, which greatly improves the charge separation with increased lifetime of excited electrons and holes 81, 82. $\mathrm{Fe}^{2+}$ ions are relatively unstable when compared to $\mathrm{Fe}^{3+}$ ions, which have half-filled $3 \mathrm{~d}^{5}$ orbital. Therefore, the trapped charges can easily release from $\mathrm{Fe}^{2+}$ ions and then migrate to the surface to initiate the photocatalytic reaction. In addition, $\mathrm{Fe}^{2+}$ ions can be oxidized to $\mathrm{Fe}^{3+}$ ions by transferring electrons to absorbed molecular oxygen in the reaction solution, resulting in the formation of reactive superoxide radicals $\left(\cdot \mathrm{O}_{2}^{-}\right)$which can further degrade $\mathrm{RhB}[82]$.

The $\mathrm{Fe} / \mathrm{MgO}$ nanoparticles are supposed to be well attached to the rGO sheets as can be seen in the TEM images. Due to its excellent electron conductivity, graphene can greatly promote interfacial charge transfer and significantly improve the photoactivity of $\mathrm{Fe} / \mathrm{MgO}-$ graphene nanocomposites. Furthermore, due to the $\pi-\pi$ conjugated interactions between the RhB molecules and the graphene rings, graphene sheets have an exceptional ability to adsorb dye molecules in the aqueous medium [7. Besides, density-functional theory (DFT) calculations revealed that the work function (WF) of graphene is $4.42 \mathrm{eV}$, indicating the redox potential of $\mathrm{rGO} / \mathrm{rGO}^{-}$ is $(-0.08 \mathrm{eV}$ versus $\mathrm{NHE})$ more positive than the CB potential of $\mathrm{Fe} / \mathrm{MgO}(-1.24 \mathrm{eV}$ versus NHE) 83, 84. This will result in a thermodynamically convenient transfer of photogenerated electrons from the $\mathrm{CB}$ of $\mathrm{Fe} / \mathrm{MgO}$ to the rGO surface, giving the electrons more opportunities to interact with reactants and participate in photocatalytic reactions. The photo generated electron 
Table II. An overview of the photocatalytic $\mathrm{H}_{2}$ production ability of photocatalysts reported in recent literature.

\begin{tabular}{|c|c|c|c|c|}
\hline Photocatalyst & Light source & Reactant solution & $\begin{array}{l}\mathrm{H}_{2} \quad \text { yield } \\
\left(\mu \mathrm{mol} \mathrm{g}^{-1} \mathrm{~h}^{-1}\right)\end{array}$ & Reference (year) \\
\hline $\mathrm{SrTiO}_{3}$-rGO & $300 \mathrm{~W}$ Xe lamp & $\mathrm{H}_{2} \mathrm{PtCl}_{6}$ & 363 & 70] $(2016)$ \\
\hline $\mathrm{ZnO} / \mathrm{rGO}$ & $300 \mathrm{~W}$ Xe lamp & Triethylamine, alcohol & 616 & 77] $(2016)$ \\
\hline $\mathrm{TiO}_{2}$-rGO & $300 \mathrm{~W}$ Xe lamp; $\lambda>300 \mathrm{~nm}$ & Methanol & 720 & 78 \\
\hline $\mathrm{TiO}_{2} / \mathrm{Pt} / \mathrm{rGO}$ & 4 Philips PL-S (9 W) lamp; $315<\lambda<400 \mathrm{~nm}$ & Methanol & 259 & 79] (2018) \\
\hline $\mathrm{MgO} / \mathrm{MgCr}_{2} \mathrm{O}_{4}$ & Hg lamp; $\lambda \geq 400 \mathrm{~nm}$ & Methanol & 420 & 9] $(2018)$ \\
\hline $\mathrm{Bi}_{25} \mathrm{FeO}_{40}-\mathrm{rGO}$ & $500 \mathrm{~W}$ Xe lamp; $\lambda<400 \mathrm{~nm}$ & Deionized water & 390 & 11] (2018) \\
\hline $\mathrm{CdS} / \mathrm{rGO}$ & $300 \mathrm{~W}$ Xe lamp; $\lambda>420 \mathrm{~nm}$ & $\mathrm{Na}_{2} \mathrm{~S}, \mathrm{Na}_{2} \mathrm{SO}_{3}$ & 500 & 71] (2019) \\
\hline $\mathrm{TiO}_{2} / \mathrm{rGO} / \mathrm{LaFeO}_{3}$ & $300 \mathrm{~W}$ Xe lamp & Methanol & 893 & [8] $(2019)$ \\
\hline $\mathrm{PANI}^{-\mathrm{TiO}_{2}} / \mathrm{rGO}$ & $300 \mathrm{~W}$ Xe lamp & Triethanolamine & 806 & 7] $(2020)$ \\
\hline $\mathrm{TiO}_{2} / \mathrm{In}_{0.5} \mathrm{WO}_{3}-\mathrm{rGO}$ & Xe arc lamp & Glycerol & 304 & 12] (2021) \\
\hline $\mathrm{Fe} / \mathrm{MgO}-\mathrm{rGO}$ & $500 \mathrm{~W}$ Xe lamp & Deionized water & 432 & Present work \\
\hline
\end{tabular}

in $\mathrm{rGO}$ could react with adsorbed $\mathrm{O}_{2}$ to form $\cdot \mathrm{O}_{2}^{-}$radicals. The majority of $\cdot \mathrm{O}_{2}^{-}$radicals will be involved in the degradation of $\mathrm{RhB}$ molecules, while others may react with $\mathrm{H}_{2} \mathrm{O}$ to produce $\cdot \mathrm{OH}$ radicals. Consequently, the produced $\cdot \mathrm{O}_{2}^{-}$and $\cdot \mathrm{OH}$ radicals, as well as photogenerated electrons and holes will react with dye molecules and degrade it into non-toxic byproducts.

The tentative mechanism can be summarized as follows

$$
\begin{gathered}
\mathrm{Fe} / \mathrm{MgO}+\mathrm{h} \nu \rightarrow \mathrm{Fe}\left(\mathrm{e}^{-}\right) / \mathrm{MgO}\left(\mathrm{h}^{+}\right) \\
\mathrm{Fe}^{3+}+\mathrm{e}^{-} \rightarrow \mathrm{Fe}^{2+} \\
\mathrm{Fe}^{2+}+\mathrm{O}_{2} \rightarrow \mathrm{Fe}^{3+}+\cdot \mathrm{O}_{2}^{-} \\
\mathrm{MgO}\left(\mathrm{h}^{+}\right)+\mathrm{H}_{2} \mathrm{O} \rightarrow \mathrm{H}^{+}+\cdot \mathrm{OH} \\
\mathrm{e}^{-}+\mathrm{rGO} \rightarrow \mathrm{rGO}\left(\mathrm{e}^{-}\right) \\
\mathrm{rGO}\left(\mathrm{e}^{-}\right)+\mathrm{O}_{2} \rightarrow \cdot \mathrm{O}_{2}^{-}
\end{gathered}
$$

$\mathrm{RhB}+\left(\cdot \mathrm{O}_{2}^{-}+\cdot \mathrm{OH}+\mathrm{e}^{-}+\mathrm{h}^{+}\right) \rightarrow$ Degraded products

A similar model can be suggested for understanding the mechanism behind the superior ability of $\mathrm{Fe} / \mathrm{MgO}-\mathrm{rGO}(500)$ nanocomposite for solar $\mathrm{H}_{2}$ production through water splitting (ESI Fig. S7). For successful water splitting reaction to take place, CBM potential of the photocatalyst needs to be lower than the proton reduction potential (0 eV vs NHE) whereas the VBM potential needs to be greater than the oxidation potential of hydroxyl ion (1.23 eV vs NHE) [55]. Notably, our rGO supported nanocomposites fulfil both requirements efficiently. Therefore, the photogenerated holes from the nanocomposite with sufficient potential can react with the water molecules and produce $\mathrm{H}^{+}$along with $\mathrm{O}_{2}$ and the photogenerated electrons evolve $\mathrm{H}_{2}$ gas by reducing $\mathrm{H}^{+}$.

\section{CONCLUSIONS}

We have demonstrated that incorporation of a potential electron acceptor and reservoir rGO is an excellent choice of material to maintain $\mathrm{e}^{-}$and $\mathrm{h}^{+}$pairs separated for a long period by suppression of charge carrier recombination. This also resulted in an improved optical absorption and reduction in band gap, all of which contributed to enhance the photocatalytic performance of the $\mathrm{Fe} / \mathrm{MgO}-\mathrm{rGO}$ nanocomposites as compared to $\mathrm{MgO}$ and widely used P25 nanoparticles. Notably, the hydrogen production capability via water splitting of the synthesized nanocomposites, particularly thermally treated $\mathrm{Fe} / \mathrm{MgO}-\mathrm{rGO}$ at $500{ }^{\circ} \mathrm{C}$ is significantly higher compared to that of $\mathrm{MgO}, \mathrm{Fe} / \mathrm{MgO}$, commercial widely used P25 nanoparticles as well as other related rGO based composites. Based on the current findings, the synthesized nanocomposites can be considered as a promising candidate for numerous photocatalytic applications such as purification of water by removing harmful pollutants, solar water disinfection, and carbon-free hydrogen production via renewable sources like water and solar energy. Our findings with profound insights into the kinetics of charge transfer may pave the way for researchers to construct and optimize new graphenebased nanocomposite photocatalysts to fulfill the modern technological requirements in environmental and energy-related applications. 


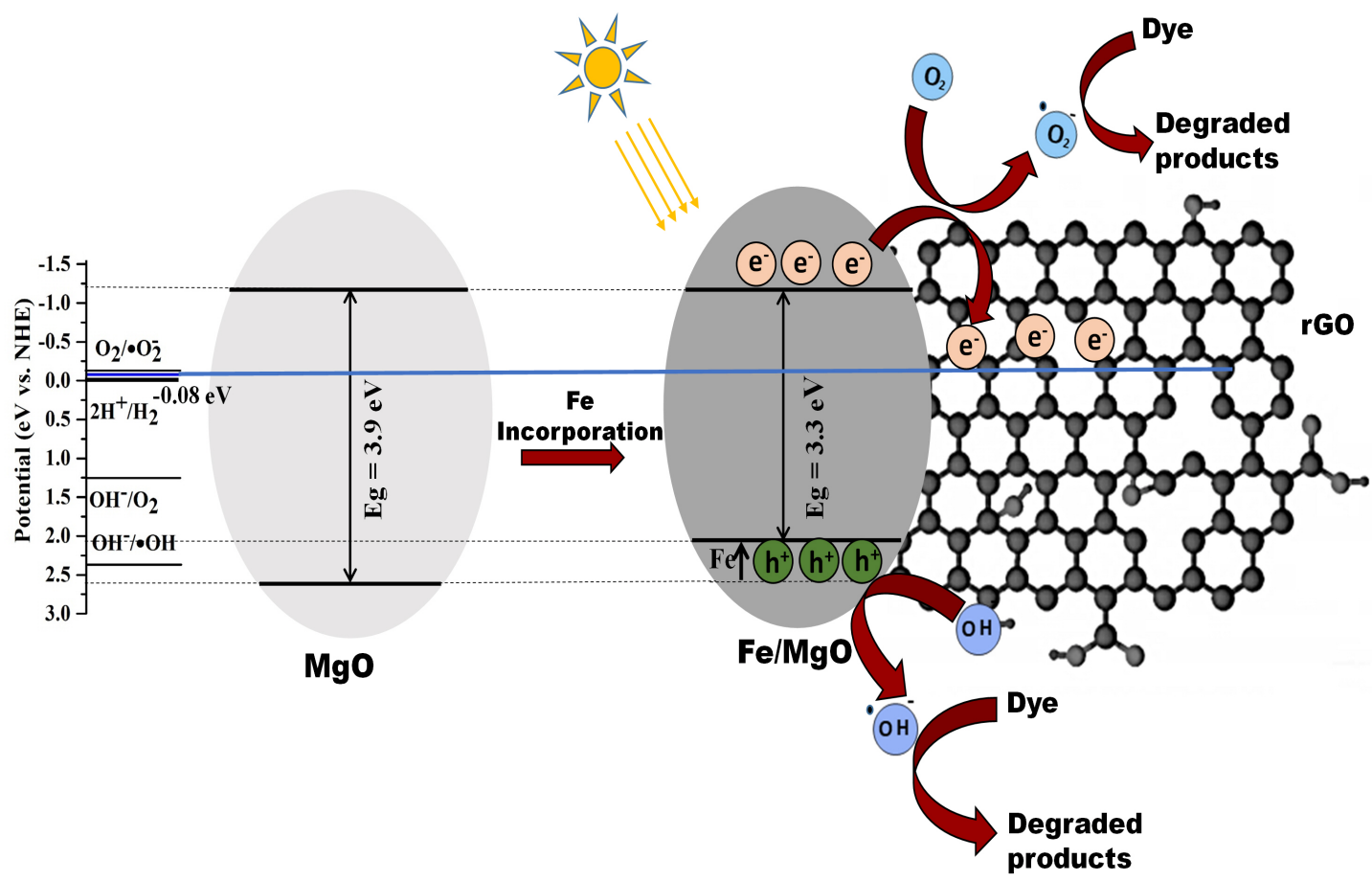

Figure 8. Schematic representation of electron transfer mechanism in the photodegradation of $\mathrm{RhB}$ over $\mathrm{Fe} / \mathrm{MgO}-\mathrm{rGO}$ nanocomposites under solar irradiation

\section{ACKNOWLEDGEMENTS}

We sincerely acknowledge Committee for Advanced Studies and Research (CASR), Bangladesh University of Engineering and Technology for financial assistance. The Atomic Energy Center, Dhaka is also acknowledged for providing TEM facilities.

\section{APPENDIX A. SUPPLEMENTARY DATA}

Supplementary data to this article can be found online.

\section{DATA AVAILABILITY}

The raw and processed data required to reproduce these findings cannot be shared at this time due to technical or time limitations.
[1] Jain IP. Hydrogen the fuel for 21st century. Int J Hydrogen Energy 2009;34(17):7368-78. https://doi.org/10.1016/j.ijhydene.2009.05.093.

[2] Tama AM, Das S, Dutta S, Bhuyan MD, Islam $\mathrm{MN}$, Basith MA. $\mathrm{MoS}_{2}$ nanosheet incorporated $\alpha-\mathrm{Fe}_{2} \mathrm{O}_{3} / \mathrm{ZnO}$ nanocomposite with enhanced photocatalytic dye degradation and hydrogen production ability. RSC Adv 2019;9(69):40357-67. https://doi.org/10.1039/C9RA07526G.

[3] Tong H, Ouyang S, Bi Y, Umezawa N, Oshikiri M, Ye J. Nano-photocatalytic materials: possibilities and challenges. Adv Mater 2012;24(2):229-51. https://doi.org/10.1002/adma.201102752.

[4] Abe JO, Popoola AP, Ajenifuja E, Popoola OM. Hydrogen energy, economy and storage: review and recommendation. Int J Hydrogen Energy 2019;44(29):1507286.https://doi.org/10.1016/j.ijhydene.2019.04.068.

[5] Fu X, Huang C, Wen J, Du Y, Zheng X. Onepot sulfurized synthesis of $\mathrm{ZnIn}_{2} \mathrm{~S}_{4} / \mathrm{S}, \mathrm{N}$-codoped carbon composites for solar light driven water splitting. Int J Hydrogen Energy 2021;46(34):17697-17707. https://doi.org/10.1016/j.ijhydene.2021.02.177.

[6] Das S, Dutta S, Tama AM, Basith MA. Nanostructured $\mathrm{LaFeO}_{3}-\mathrm{MoS}_{2}$ for efficient pho- 
todegradation and photocatalytic hydrogen evolution. Mater Sci Eng B 2021;271:115295. https://doi.org/10.1016/j.mseb.2021.115295.

[7] Ma J, Dai J, Duan Y, Zhang J, Qiang L, Xue J. Fabrication of PANI-TiO $2 /$ rGO hybrid composites for enhanced photocatalysis of pollutant removal and hydrogen production. Renew Energy 2020;156:1008-18. https://doi.org/10.1016/j.renene.2020.04.104.

[8] Lv T, Wang H, Hong W, Wang $\mathrm{P}$, Jia L. In situ self-assembly synthesis of sandwich-like $\mathrm{TiO}_{2} /$ reduced graphene oxide $/ \mathrm{LaFeO}_{3}$ Z-scheme ternary heterostructure towards enhanced photocatalytic hydrogen production. Mol Catal 2019 ;475:110497. https://doi.org/10.1016/j.mcat.2019.110497.

[9] Nayak S, Pradhan AC, Parida KM. Topotactic transformation of solvated $\mathrm{MgCr}-\mathrm{LDH}$ nanosheets to highly efficient porous $\mathrm{MgO} / \mathrm{MgCr}_{2} \mathrm{O}_{4}$ nanocomposite for photocatalytic $\mathrm{H}_{2}$ evolution. Inorg Chem 2018;57(14):864661. http://dx.doi.org/10.1021/acs.inorgchem.8b01517.

[10] Winter CJ. Hydrogen energy-Abundant, efficient, clean: A debate over the energy-system-ofchange. Int J Hydrogen Energy 2009;34(14):S1-52. https://doi.org/10.1016/j.ijhydene.2009.05.063.

[11] Basith MA, Ahsan R, Zarin I, Jalil MA. Enhanced photocatalytic dye degradation and hydrogen production ability of $\mathrm{Bi}_{25} \mathrm{FeO}_{40}$-rGO nanocomposite and mechanism insight. Sci Rep 2018;8(1):1-11. https://doi.org/10.1038/s41598-018-29402-w.

[12] Shaheer AM, Vinesh V, Lakhera SK, Neppolian B. Reduced graphene oxide as a solid-state mediator in $\mathrm{TiO}_{2} / \mathrm{In}_{0.5} \mathrm{WO}_{3}$ S-scheme photocatalyst for hydrogen production. Sol Energy 2021;213:260-70. https://doi.org/10.1016/j.solener.2020.11.030.

[13] Jain IP, Lal C, Jain A. Hydrogen storage in $\mathrm{Mg}$ : a most promising material. Int J Hydrogen Energy 2010;35(10):5133-44. https://doi.org/10.1016/j.ijhydene.2009.08.088.

[14] Bičáková O, Straka P. Production of hydrogen from renewable resources and its effectiveness. Int J Hydrogen Energy 2012;37(16):11563-78. https://doi.org/10.1016/j.ijhydene.2012.05.047.

[15] Moriarty P, Honnery D. Prospects for hydrogen as a transport fuel. Int $\mathrm{J} \mathrm{Hy}-$ drogen Energy 2019;44(31):16029-37. https://doi.org/10.1016/j.ijhydene.2019.04.278.

[16] Cao L, Iris KM, Xiong X, Tsang DC, Zhang S, Clark JH, $\mathrm{Hu} \mathrm{C}, \mathrm{Ng}$ YH, Shang J, Ok YS. Biorenewable hydrogen production through biomass gasification: A review and future prospects. Environ Res 2020;186:109547. https://doi.org/10.1016/j.envres.2020.109547.

[17] Dawood F, Anda M, Shafiullah GM. Hydrogen production for energy: An overview. Int J Hydrogen Energy 2020;45(7):3847-69. https://doi.org/10.1016/j.ijhydene.2019.12.059.

[18] Reddy P, Cui H, Vattikuti SP, Suh Y, Park SH. Influence of $\mathrm{Gd}$ doping on the visible-light photocatalytic activity and magnetic properties of $\mathrm{BiFeO}_{3}$ particles. Mater Res Express 2019;6(11):115044. https://doi.org/10.1088/2053-1591/ab463d.

[19] Patil SB, Naik HB, Nagaraju G, Viswanath R, Rashmi SK. Sugarcane juice mediated eco-friendly synthesis of visible light active zinc ferrite nanoparticles: Application to degradation of mixed dyes and antibacterial activities. Mater Chem Phys 2018;212:351-62. https://doi.org/10.1016/j.matchemphys.2018.03.038.

[20] Yang H, Yang J. Photocatalytic degradation of rhodamine $\mathrm{B}$ catalyzed by $\mathrm{TiO}_{2}$ films on a capillary column. RSC adv 2018;8(22):11921-9. https://doi.org/10.1039/C8RA00471D.

[21] Peña PA, Ortega DR, Araque DG, Gordillo AH, Zanella R, Reguera E. Boosting the photocatalytic hydrogen production of $\mathrm{TiO}_{2}$ by using copper hexacyanocobaltate as co-catalyst. Int J Hydrogen Energy 2021;46(17):10312-23. https://doi.org/10.1016/j.ijhydene.2020.12.135.

[22] Galdámez-Martínez A, Bai Y, Santana G, Sprick RS, Dutt A. Photocatalytic hydrogen production performance of 1-D $\mathrm{ZnO}$ nanostructures: Role of structural properties. Int J Hydrogen Energy 2020;45(56):3194251. https://doi.org/10.1016/j.ijhydene.2020.08.247.

[23] Lang D, Cheng F, Xiang Q. Enhancement of photocatalytic $\mathrm{H}_{2}$ production activity of $\mathrm{CdS}$ nanorods by cobalt-based cocatalyst modification. Catal Sci Technol 2016;6(16):6207-16. https://doi.org/10.1039/C6CY00753H.

[24] Saadetnejad D, Ylldırım R. Photocatalytic hydrogen production by water splitting over $\mathrm{Au} / \mathrm{Al}-$ $\mathrm{SrTiO}_{3}$. Int J Hydrogen Energy 2018;43(2):1116-22. https://doi.org/10.1016/j.ijhydene.2017.10.154.

[25] Solakidou M, Giannakas A, Georgiou Y, Boukos N, Louloudi M, Deligiannakis Y. Efficient photocatalytic water-splitting performance by ternary $\mathrm{CdS} / \mathrm{Pt}-\mathrm{N}-\mathrm{TiO}_{2}$ and $\mathrm{CdS} / \mathrm{Pt}-\mathrm{N}, \quad \mathrm{F}-\mathrm{TiO}_{2}$ : interplay between CdS photo corrosion and $\mathrm{TiO}_{2}$ dopping. Appl Catal B 2019 ;254:194-205. https://doi.org/10.1016/j.apcatb.2019.04.091.

[26] Mazierski P, Malankowska A, Kobylanski M, Diak M, Kozak M, Winiarski MJ, Klimczuk T, Lisowski W, Nowaczyk G, Zaleska-Medynska A. Photocatalytically active $\mathrm{TiO}_{2} / \mathrm{Ag}_{2} \mathrm{O}$ nanotube arrays interlaced with silver nanoparticles obtained from the one-step anodic oxidation of Ti-Ag alloys. ACS Catal 2017;7(4):2753-64. https://doi.org/10.1021/acscatal.7b00056.

[27] Mohamed RM, Shawky A, Mkhalid IA. Facile synthesis of $\mathrm{MgO}$ and $\mathrm{Ni}-\mathrm{MgO}$ nanostructures with enhanced adsorption of methyl blue dye. J Phys Chem Solids 2017;101:50-7. https://doi.org/10.1016/j.jpcs.2016.10.009.

[28] Moussavi G, Mahmoudi M. Removal of azo and anthraquinone reactive dyes from industrial wastewaters using $\mathrm{MgO}$ nanoparticles. J Hazard Mater 2009 ;168(2-3):806-12. https://doi.org/10.1016/j.jhazmat.2009.02.097.

[29] Sutradhar N, Sinhamahapatra A, Pahari SK, Pal P, Bajaj HC, Mukhopadhyay I, Panda AB. Controlled synthesis of different morphologies of $\mathrm{MgO}$ and their use as solid base catalysts. J Phys Chem C 2011;115(25):12308-16. https://doi.org/10.1021/jp2022314.

[30] Mageshwari K, Mali SS, Sathyamoorthy R, Patil PS. Template-free synthesis of $\mathrm{MgO}$ nanoparticles for effective photocatalytic ap- 
plications. Powder Technol 2013;249:456-62. https://doi.org/10.1016/j.powtec.2013.09.016.

[31] Pinilla JL, Utrilla R, Karn RK, Suelves I, Lázaro MJ, Moliner R, García AB, Rouzaud JN. High temperature iron-based catalysts for hydrogen and nanostructured carbon production by methane decomposition. Int J Hydrogen Energy 2011;36(13):7832-43. https://doi.org/10.1016/j.ijhydene.2011.01.184.

[32] Ba-Abbad MM, Kadhum AA, Mohamad AB, Takriff MS, Sopian K. Visible light photocatalytic activity of $\mathrm{Fe}^{3+}$-doped $\mathrm{ZnO}$ nanoparticle prepared via sol-gel technique. Chemosphere 2013;91(11):1604-11. https://doi.org/10.1016/j.chemosphere.2012.12.055.

[33] Othmen WB, Hamdi A, Addad A, Sieber B, Elhouichet H, Szunerits S, Boukherroub R. Fe-doped $\mathrm{SnO}_{2}$ decorated reduced graphene oxide nanocomposite with enhanced visible light photocatalytic activity. J Photochem Photobiol A 2018;367:145-55. https://doi.org/10.1016/j.jphotochem.2018.08.016.

[34] Mansingh S, Padhi DK, Parida KM. Enhanced photocatalytic activity of nanostructured $\mathrm{Fe}$ doped $\mathrm{CeO}_{2}$ for hydrogen production under visible light irradiation. Int J Hydrogen Energy 2016;41(32):14133-46. https://doi.org/10.1016/j.ijhydene.2016.05.191.

[35] Borhade AV, Kanade KG, Tope DR, Patil MD. A Comparative study on synthesis, characterization and photocatalytic activities of $\mathrm{MgO}$ and $\mathrm{Fe} / \mathrm{MgO}$ nanoparticles. Res Chem Intermed 2012;38(8):1931-46. https://doi.org/10.1007/s11164-012-0515-z.

[36] Ramirez S, Chan K, Hernandez R, Recinos E, Hernandez E, Salgado R, Khitun AG, Garay JE, Balandin AA. Thermal and magnetic properties of nanostructured densified ferrimagnetic composites with graphene-graphite fillers. Mater Des 2017;118:75-80. https://doi.org/10.1016/j.matdes.2017.01.018.

[37] Xu YF, Yang MZ, Chen BX, Wang XD, Chen HY, Kuang $\mathrm{DB}$, Su CY. A $\mathrm{CsPbBr}_{3}$ perovskite quantum dot/graphene oxide composite for photocatalytic $\mathrm{CO}_{2}$ reduction. J Am Chem Soc 2017;139(16):5660-3. https://doi.org/10.1021/jacs.7b00489.

[38] Marlinda AR, Yusoff N, Sagadevan S, Johan MR. Recent developments in reduced graphene oxide nanocomposites for photoelectrochemical water-splitting applications. Int J Hydrogen Energy 2020;45(21):11976-94. https://doi.org/10.1016/j.ijhydene.2020.02.096.

[39] Purwajanti S, Huang X, Liu Y, Yang Y, Noonan O, Song $\mathrm{H}$, Zhang J, Zhang J, Fu J, Liang C, Yu C. $\mathrm{Mg}(\mathrm{OH})_{2}-\mathrm{MgO} @$ reduced graphene oxide nanocomposites: the roles of composition and nanostructure in arsenite sorption. J Mater Chem A 2017;5(46):24484-92. https://doi.org/10.1039/C7TA07629K.

[40] Gollu SR, Sharma R, Srinivas G, Kundu S, Gupta D. Incorporation of silver and gold nanostructures for performance improvement in P3HT: PCBM inverted solar cell with $\mathrm{rGO} / \mathrm{ZnO}$ nanocomposite as an electron transport layer. Org Electron 2016;29:79-87. https://doi.org/10.1016/j.orgel.2015.11.015

[41] Wang K, Tan J, Lu Z, Chen S, She X, Zhang H, Yang D. Nanoscale engineering $\mathrm{MoP} / \mathrm{Fe}_{2} \mathrm{P} / \mathrm{RGO}$ toward efficient electrocatalyst for hydrogen evolution reaction. Int J Hydrogen Energy 2018;43(30):13939-45. https://doi.org/10.1016/j.ijhydene.2018.02.012.

[42] Hafeez HY, Lakhera SK, Shankar MV, Neppolian B. Synergetic improvement in charge carrier transport and light harvesting over ternary $\mathrm{InVO}_{4}-\mathrm{g}_{-} \mathrm{C}_{3} \mathrm{~N}_{4} / \mathrm{rGO}$ hybrid nanocomposite for hydrogen evolution reaction. Int J Hydrogen Energy 2020;45(13):7530-40. https://doi.org/10.1016/j.ijhydene.2019.05.235.

[43] Sadhukhan S, Ghosh TK, Rana D, Roy I, Bhattacharyya A, Sarkar G, Chakraborty M, Chattopadhyay D. Studies on synthesis of reduced graphene oxide (RGO) via green route and its electrical property. Mater Res Bull 2016;79:41-51. https://doi.org/10.1016/j.materresbull.2016.02.039.

[44] Yu Z, Shi Z, Xu H, Ma X, Tian M, Yin J. Green chemistry: Co-assembly of tannin-assisted exfoliated low-defect graphene and epoxy natural rubber latex to form soft and elastic nacre-like film with good electrical conductivity. Carbon 2017;114:649-60. https://doi.org/10.1016/j.carbon.2016.12.049.

[45] Shi P, Wang X, Zhou X, Min Y, Fan J, Yao W. Influence of calcination temperature on the catalytic performance of $\mathrm{Co}_{3} \mathrm{O}_{4} / \mathrm{GO}$ nanocomposites for Orange II degradation. RSC Adv 2015;5(43):34125-33. https://doi.org/10.1039/C5RA02680F.

[46] Feng J, Ding Y, Guo Y, Li X, Li W. Calcination temperature effect on the adsorption and hydrogenated dissociation of $\mathrm{CO}_{2}$ over the $\mathrm{NiO} / \mathrm{MgO}$ catalyst. Fuel 2013;109:110-5. https://doi.org/10.1016/j.fuel.2012.08.028.

[47] Yeoh WM, Lee KY, Chai SP, Lee KT, Mohamed AR. Effective synthesis of carbon nanotubes via catalytic decomposition of methane: Influence of calcination temperature on metal-support interaction of $\mathrm{Co}-\mathrm{Mo} / \mathrm{MgO}$ catalyst. J Phys Chem Solids 2013;74(11):1553-9. https://doi.org/10.1016/j.jpcs.2013.05.023.

[48] Zhang H, Hu J, Xie J, Wang S, Cao Y. A solid-state chemical method for synthesizing $\mathrm{MgO}$ nanoparticles with superior adsorption properties. RSC adv 2019;9(4):2011-7. https://doi.org/10.1039/C8RA09199D.

[49] Karnaukhov TM, Vedyagin AA, Cherepanova SV, Rogov VA, Stoyanovskii VO, Mishakov IV. Study on reduction behavior of two-component $\mathrm{FeMgO}$ oxide system prepared via a sol-gel technique. Int J Hydrogen Energy 2017;42(52):30543-9. https://doi.org/10.1016/j.ijhydene.2017.11.036.

[50] Kumar A, Nazzario R, Torres-Castro L, PenaDuarte A, Tomar MS. Electrochemical properties of $\quad \mathrm{MgO}$-coated $\quad 0.5 \quad \mathrm{Li}_{2} \mathrm{MnO}_{3}-0.5 \quad \mathrm{LiNi}_{0.5} \mathrm{Mn}_{0.5} \mathrm{O}_{2}$ composite cathode material for lithium ion battery. Int J Hydrogen Energy 2015;40(14):49315.https://doi.org/10.1016/j.ijhydene.2015.01.104.

[51] Basith MA, Yesmin N, Hossain R. Low temperature synthesis of $\mathrm{BiFeO}_{3}$ nanoparticles with enhanced magnetization and promising photocatalytic performance in dye degradation and hydrogen evolution. RSC adv 2018;8(52):29613-27. https://doi.org/10.1039/c8ra04599b.

[52] Brillas E, Sirés I, Oturan MA. Electro-Fenton process and related electrochemical technologies based on Fenton's reaction chemistry. Chem Rev 2009;109(12):6570- 
631. https://doi.org/10.1021/cr900136g.

[53] Soltani T, Tayyebi A, Lee BK. Photolysis and photocatalysis of tetracycline by sonochemically heterojunctioned $\mathrm{BiVO}_{4} /$ reduced graphene oxide under visiblelight irradiation. J Environ Manage 2019;232:713-21. https://doi.org/10.1016/j.jenvman.2018.11.133.

[54] Paulchamy B, Arthi G, Lignesh BD. A simple approach to stepwise synthesis of graphene oxide nanomaterial. J Nanomed Nanotechnol 2015;6(1):1. https://doi.org/ 10.4172/2157-7439.1000253.

[55] Jalil MA, Chowdhury SS, Alam SM, Yousuf SMEH, Ashik EK, Firoz SH, Basith MA. Temperaturedependent phase transition and comparative investigation on enhanced magnetic and optical properties between sillenite and perovskite bismuth ferriterGO nanocomposites. J Appl Phys 2017;122(8):084902. https://doi.org/10.1063/1.4985840.

[56] Devaraja PB, Avadhani DN, Prashantha SC, Nagabhushana H, Sharma SC, Nagabhushana BM, Nagaswarupa HP. Synthesis, structural and luminescence studies of magnesium oxide nanopowder. Spectrochim Acta A 2014;118:847-51. http://dx.doi.org/10.1016/j.saa.2013.08.050.

[57] Petnikota S, Srikanth VV, Toh JJ, Srinivasan M, Bobba CV, Adams S, Reddy MV. Electrochemistryrelated aspects of safety of graphene-based nonaqueous electrochemical supercapacitors: a case study with $\mathrm{MgO}$-decorated few-layer graphene as an electrode material. New J Chem 2019;43(25):9793-801. https://doi.org/10.1039/C9NJ00991D.

[58] Ganguly A, Sharma S, Papakonstantinou P, Hamilton J. Probing the thermal deoxygenation of graphene oxide using high-resolution in situ X-ray-based spectroscopies. J Phys Chem C 2011;115(34):17009-19. https://doi.org/10.1021/jp203741y.

[59] Jin M, Jeong HK, Yu WJ, Bae DJ, Kang BR, Lee YH. Graphene oxide thin film field effect transistors without reduction. J Phys D: Appl Phys 2009;42(13):135109. https://doi.org/10.1088/0022-3727/42/13/135109.

[60] Kayani ZN, Saleemi F, Batool I. Effect of calcination temperature on the properties of $\mathrm{ZnO}$ nanoparticles. Appl Phys A 2015 ;119(2):713-20. https://doi.org/10.1007/s00339-015-9019-1.

[61] Sinornate W, Mimura H, Pecharapa W. Structural, Morphological, Optical, and Electrical Properties of Sol-Gel Derived Sb-Doped $\mathrm{ZnO}$ Thin Films Annealed Under Different Atmospheres. Phys Status Solidi 2021;218(1):2000233. https://doi.org/ $10.1002 /$ pssa.202000233.

[62] Devaraja PB, Avadhani DN, Nagabhushana H, Prashantha SC, Sharma SC, Nagabhushana BM, Nagaswarupa HP, Prasad BD. Luminescence properties of $\mathrm{MgO}: \mathrm{Fe}^{3+}$ nanopowders for WLEDs under NUV excitation prepared via propellant combustion route. J Radiant Res Appl Sci 2015;8(3):362-73. http://dx.doi.org/10.1016/j.jrras.2015.02.001.

[63] Turabik M, Simsek UB. Effect of synthesis parameters on the particle size of the zero valent iron particles. Inorg Nano-Met Chem 2017;47(7):1033-43. https://doi.org/10.1080/15533174.2016.1219869.
[64] Li X, Staykov A, Yoshizawa K. Orbital views of the electron transport through polycyclic aromatic hydrocarbons with different molecular sizes and edge type structures. J Phys Chem C 2010;114(21):9997-10003. https://doi.org/10.1021/jp102280r.

[65] Li W, Bu Y, Jin H, Wang J, Zhang W, Wang S, Wang J. The preparation of hierarchical flowerlike $\mathrm{NiO} /$ reduced graphene oxide composites for high performance supercapacitor applications. Energ Fuel 2013;27(10):6304-10. https://doi.org/10.1021/ef401190b.

[66] Kumar A, Kumar J. On the synthesis and optical absorption studies of nano-size magnesium oxide powder. J Phys Chem Solids 2008;69(11):2764-72. https://doi.org/10.1016/j.jpcs.2008.06.143.

[67] Nanakkal AR, Alexander LK. Graphene/BiVO $4 / \mathrm{TiO}_{2}$ nanocomposite: tuning band gap energies for superior photocatalytic activity under visible light. J Mater Sci 2017;52(13):7997-8006. https://doi.org/10.1007/s10853-017-1002-0.

[68] Zhang J, Huang X, Zhang H, Xue Q, Xu H, Wang $\mathrm{L}$, Feng $\mathrm{Z}$. The effect of powder grain size on the microstructure and electrical properties of $8 \mathrm{~mol} \varkappa$ $\mathrm{Y}_{2} \mathrm{O}_{3}$-stabilized $\mathrm{ZrO}_{2}$. RSC Adv 2017;7(62):39153-9. https://doi.org/10.1039/C7RA06710K.

[69] Ghosh S, Kar P, Bhandary N, Basu S, Maiyalagan T, Sardar S, Pal SK. Reduced graphene oxide supported hierarchical flower like manganese oxide as efficient electrocatalysts toward reduction and evolution of oxygen. Int J Hydrogen Energy 2017;42(7):4111-22. http://dx.doi.org/10.1016/j.ijhydene.2016.12.008.

[70] He GL, Zhong YH, Chen MJ, Li X, Fang $\mathrm{YP}, \mathrm{Xu}$ YH. One-pot hydrothermal synthesis of $\mathrm{SrTiO}_{3}$-reduced graphene oxide composites with enhanced photocatalytic activity for hydrogen production. J Mol Catal A 2016;423:70-6. https://doi.org/10.1016/j.molcata.2016.05.025.

[71] Hareesh K, Dhole SD, Phase DM, Williams JF. One-step bacterial assisted synthesis of $\mathrm{CdS} / \mathrm{rGO}$ nanocomposite as Hydrogen production catalyst. Mater Res Bull 2019;110:82-9. https://doi.org/10.1016/j.materresbull.2018.10.012.

[72] Arshad A, Iqbal J, Siddiq M, Mansoor Q, Ismail M, Mehmood F, Ajmal M, Abid Z. Graphene nanoplatelets induced tailoring in photocatalytic activity and antibacterial characteristics of $\mathrm{MgO} /$ graphene nanoplatelets nanocomposites. J Appl Phys 2017;121(2):024901. https://doi.org/10.1063/1.4972970.

[73] Gayathri S, Jayabal P, Kottaisamy M, Ramakrishnan V. Synthesis of $\mathrm{ZnO}$ decorated graphene nanocomposite for enhanced photocatalytic properties. J Appl Phys 2014;115(17):173504. https://doi.org/10.1063/1.4874877.

[74] Isari AA, Payan A, Fattahi M, Jorfi S, Kakavandi B. Photocatalytic degradation of rhodamine $\mathrm{B}$ and real textile wastewater using Fe-doped $\mathrm{TiO}_{2}$ anchored on reduced graphene oxide $\left(\mathrm{Fe}-\mathrm{TiO}_{2} / \mathrm{rGO}\right)$ : Characterization and feasibility, mechanism and pathway studies. Appl Surf Sci 2018;462:549-64. https://doi.org/10.1016/j.apsusc.2018.08.133.

[75] Liu Z, Yin Z, Cox C, Bosman M, Qian X, Li N, Zhao H, $\mathrm{Du}$ Y, Li J, Nocera DG. Room temperature stable COx- 
free $\mathrm{H}_{2}$ production from methanol with magnesium oxide nanophotocatalysts. Sci Adv $2016 ; 2(9)$ :e1501425. https://doi.org/10.1126/sciadv.1501425.

[76] Wang X, Zhi L, Müllen K. Transparent, conductive graphene electrodes for dyesensitized solar cells. Nano lett 2008;8(1):323-7. https://doi.org/10.1021/nl072838r.

[77] Kang W, Jimeng X, Xitao W. The effects of ZnO morphology on photocatalytic efficiency of $\mathrm{ZnO} / \mathrm{RGO}$ nanocomposites. Appl Surf Sci 2016;360:270-5. https://doi.org/10.1016/j.apsusc.2015.10.190.

[78] El-Bery HM, Matsushita Y, Abdel-moneim A. Fabrication of efficient $\mathrm{TiO}_{2}$-RGO heterojunction composites for hydrogen generation via watersplitting: Comparison between RGO, $\mathrm{Au}$ and $\mathrm{Pt}$ reduction sites. Appl Surf Sci 2017;423:185-96. https://doi.org/10.1016/j.apsusc.2017.06.130.

[79] Rivero MJ, Iglesias O, Ribao P, Ortiz I. Kinetic performance of $\mathrm{TiO}_{2} / \mathrm{Pt} /$ reduced graphene oxide composites in the photocatalytic hydrogen production. Int J Hydrogen Energy 2019;44(1):101-9. https://doi.org/10.1016/j.ijhydene.2018.02.115.

[80] Nethercot Jr AH. Prediction of Fermi energies and photoelectric thresholds based on electroneg- ativity concepts. Phys Rev Lett 1974;33(18):1088. https://doi.org/10.1103/PhysRevLett.33.1088.

[81] Li J, Liu Y, Zhou Y, Liu S, Liang Y, Luo T, Dai G. Enhanced visible-light photocatalytic activity of $\mathrm{Bi}_{2} \mathrm{O}_{2} \mathrm{CO}_{2}$ nanoplates by Fe-doping in the degradation of rhodamine B. Mater Res Bull 2018;107:438-45. https://doi.org/10.1016/j.materresbull.2018.08.018.

[82] Liang J, Zhu G, Liu P, Luo X, Tan C, Jin L, Zhou J. Synthesis and characterization of Fe-doped $\quad \beta-\mathrm{Bi}_{2} \mathrm{O}_{3}$ porous microspheres with enhanced visible light photocatalytic activity. Superlattices Microstruct 2014;72:272-82. https://doi.org/10.1016/j.spmi.2014.05.005.

[83] Li Q, Li X, Wageh S, Al-Ghamdi AA, Yu J. CdS/graphene nanocomposite photocatalysts. Adv Energy Mater 2015;5(14):1500010. https://doi.org/10.1002/aenm.201500010.

[84] Chen Y, Wang Y, Zhou X, Zhao Y, Peng W. Defected graphene as effective co-catalyst of CdS for enhanced photocatalytic activities. Environ Sci Pollut Res 2020;27:26810-6. https://doi.org/10.1007/s11356020-09066-8. 